This document is confidential and is proprietary to the American Chemical Society and its authors. Do not copy or disclose without written permission. If you have received this item in error, notify the sender and delete all copies.

\title{
Comb-like ionic complexes of hyaluronic acid and alkanoylcholine surfactants as platform for drug delivery systems
}

\begin{tabular}{|r|l|}
\hline Journal: & Biomacromolecules \\
\hline Manuscript ID & bm-2018-00783c.R1 \\
\hline Manuscript Type: & Article \\
\hline Date Submitted by the Author: & 20 -Jul-2018 \\
\hline Complete List of Authors: & $\begin{array}{l}\text { Gamarra, Ana; UPC, Chemical Engineering } \\
\text { Muñoz-Guerra, Sebastián; UPC, Chemical Engineering } \\
\text { Martínez de Ilarduya, Antxon; UPC, Chem. Eng } \\
\text { Thérien-Aubin, Héloïse; Max-Planck-Institut fur Polymerforschung, } \\
\text { Landfester, Katharina; Max Planck Institute for Polymer Research, }\end{array}$ \\
\hline
\end{tabular}

\section{SCHOLARONE" \\ Manuscripts}




\section{Table of contents}

\section{Cytotoxicity}

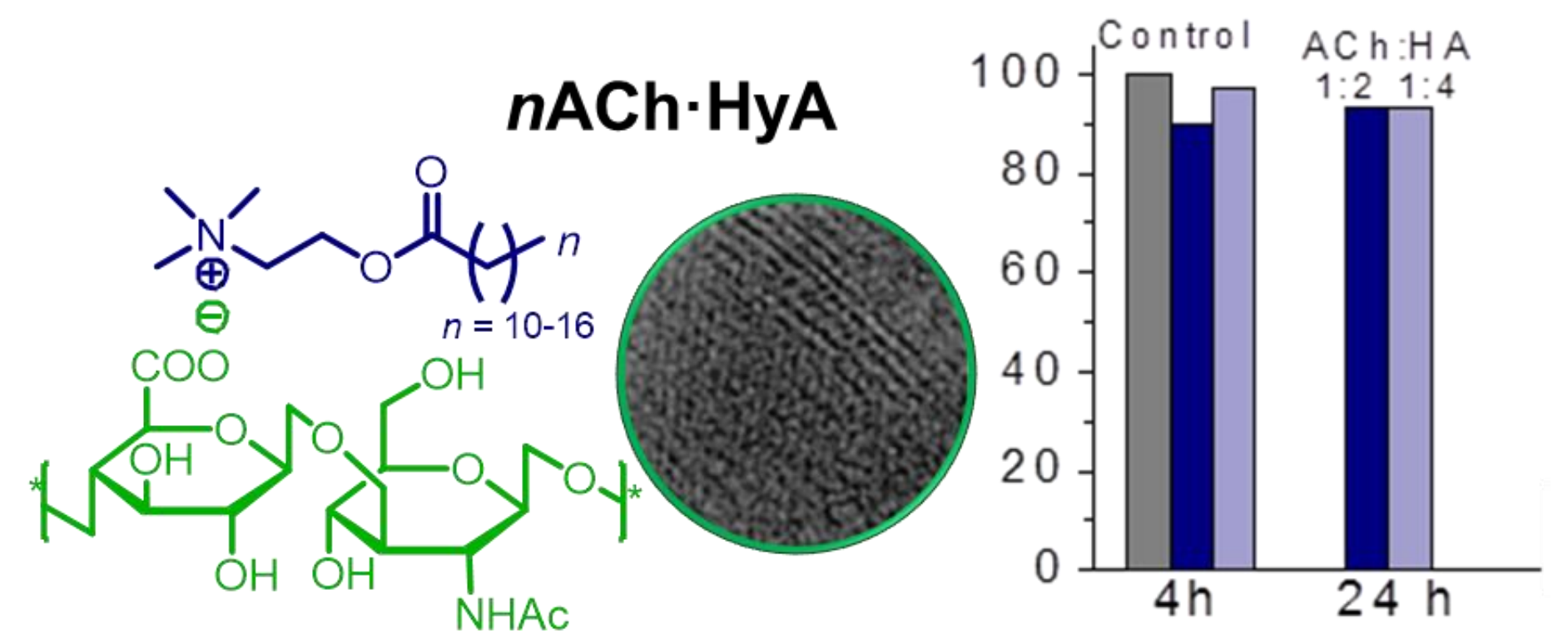




\title{
Comb-like ionic complexes of hyaluronic acid and
}

\section{alkanoylcholine surfactants as platform for drug}

\author{
delivery systems
}

\author{
Ana Gamarra, ${ }^{a}$ Sebastián Muñoz-Guerra, ${ }^{a} *$ Antxon Martínez de Ilarduya ${ }^{a}$ \\ Héloïse Thérien-Aubin, ${ }^{b}$ Katharina Landfester ${ }^{b}$ \\ ${ }^{a}$ Universitat Politècnica de Catalunya, ETSEIB, Diagonal 647, 08028 Barcelona, Spain. \\ ${ }^{\mathrm{b}}$ Max Planck Institute for Polymer Research, Ackermannweg 10, 55128 Mainz, Germany
}

Non-toxic alkanoylcholine soaps $(n \mathrm{ACh})$ were synthesized from choline and fatty acids with numbers of carbons $n$ equal to $12,14,16$ and 18, the latter including both saturated and 9-cis unsaturated alkanoyl chains. Coupling of $n \mathrm{ACh}$ with hyaluronic acid (HyA) rendered comb-like ionic complexes $n \mathrm{ACh} \cdot \mathrm{HyA}$ that were non-water soluble. The complexes were thermally stable up to temperatures above $200{ }^{\circ} \mathrm{C}$ but readily degraded by water, in particular when hyaluronidases were present in the aqueous medium. In the solid state, these complexes were self-assembled in a biphasic layered structure in which the surfactant and the polysaccharide 
phases were alternating regularly with a periodicity dependent on the length of the alkanoyl chain. The paraffinic phase was found to be crystallized in saturated complexes with $n \geq 14$ but only $18 \mathrm{ACh} \cdot \mathrm{HyA}$ showed reversible melting-crystallization when subjected to cyclic heatingcooling treatment. Nanoparticles with diameters in the $50-150 \mathrm{~nm}$ range were prepared by ionotropic gelation from unbalanced $18 \mathrm{ACh} \cdot \mathrm{HyA}$ complexes with surfactant:HyA ratios of 0.5 and 0.25 . These nanoparticles were also structured in layers, swelled slowly in water, and were shown to be non-cytotoxic in in vitro assays against macrophages cells. It was also shown that the anticancer drug Doxorubicin was efficiently encapsulated in both films and NPs of 18ACh·HyA and its release was shown to be almost linear and complete after one day of incubation in physiological medium. The $n \mathrm{ACh} \cdot \mathrm{HyA}$ complexes constitute a highly promising biocompatible/biodegradable platform for the design of systems suitable for drug transport and targeting delivery in anticancer chemotherapy.

\section{INTRODUCTION}

Hyaluronic acid (HyA) is a mucopolysaccharide ubiquitous in the human body where it plays an essential physiological role as one of the main components of the extracellular matrix and synovial fluids. ${ }^{1,2}$ HyA promotes inflammation and therefore contributes importantly to regulate reaction associated with injury., ${ }^{3,4}$ Due to its distinctive properties such as good mucoadhesion, high viscoelasticity, and extraordinary capacity to hold water, HyA has traditionally received great attention as a biomaterial for biomedical applications, in particular in arthritis treatment and surgery. ${ }^{5,6}$ Additionally HyA displays excellent biocompatibility and biodegradability, and it is able to interact with specific cells by binding to $\mathrm{CD} 44^{7,8}$ and $\mathrm{RHAMM}^{8}$ receptors, which are over-expressed at the surface of a variety of tumor cell. This unique behavior has largely encouraged the interest for HyA as drug carriers for targeted drug delivery research, especially 
for cancer chemotherapy. ${ }^{9-11}$ The applicability of HyA in drug delivery is however hampered by its great affinity for water and high degradation rate under physiological conditions. HyA has a half-life of about $2-5$ min in the bloodstream ${ }^{12}$ and its daily turnover in the human body is extremely rapid (in an adult of $70 \mathrm{~kg}$ it amounts to about $5 \mathrm{~g}$ ). A number of strategies based on the chemical modification of the carboxylate and hydroxyl groups of HyA have been developed for overcoming such limitations and broadening its potential in biomedicine. ${ }^{13,14}$

Polymer nanoparticles (NPs) able to load drugs, to preserve their activity, and to release them at a specific site of action in a sustained manner while the polymer is degraded into non-toxic fragments, are today sought after systems for cancer chemotherapy. Despite recent research efforts in this field, adverse effects such as insufficient delivery specificity and poor flow stability are still associated with drug-loaded nanoparticles. HyA is viewed as a very promising candidate to circumvent these effects because of its dual ability to form a water-compatible outer-shell of the NPs due to its hydrophilic nature, and because of its targeting function acting as a ligand for CD44 or RAHMM receptors expressed in cancer cells. ${ }^{15}$ Consequently, a wide variety of approaches based on amphiphilic derivatives of HyA prepared by taking benefit from the functionality present in this polysaccharide, have been explored to design core-shell NPs. ${ }^{16}$ In one popular approach, HyA-based NPs consisted of a hydrophobic preformed particle, made of a typical biodegradable polymer, coated with HyA. In other cases, HyA was chemically modified with a hydrophobic reagent to generate an amphiphilic structure able to self-assemble in a nanosized carrier and where the HyA-moiety was exposed on the surface of the resulting NP.

In contrast with conventional HyA-NPs synthetic techniques based on the covalent modification of the HyA, a new class of HyA nanocarriers, based on ionic complexes of hyaluronate and positive-charged compounds, has recently emerged. This approach offers 
simplicity as a remarkable advantage since chemical linkages are avoided in the construction of the amphiphilic structure. The ability of these systems to form stable ionic coupled nanostructures is highly depending on the hydrophilic-hydrophobic balance of the drug. Spherical NPs made of coupled cisplatin-HyA with a size around 100-200 nm were first reported by Jeong et al in $2008 .{ }^{17}$ These NPs were prepared by simple mixing of cisplatin with an aqueous solution of HyA and they delivered the drug, continuously, for 4 days. Colloidal dispersions made of doxorubicin (DOX) coupled with HyA with a drug content of $60 \%$ were later reported by Battistine et al. ${ }^{18}$. These complexes showed a high internalization in cancer cells and a rather slow drug release. In some cases, DOX-HyA complexes were covered with a phospholipid bilayer to create encapsulated liposomal carriers with a size of $\sim 130 \mathrm{~nm} .{ }^{19}$ These DOX-HyA-LP systems displayed remarkable drug-administration properties such as well-sustained release profile, improved cell uptake, and reduced multi-organ toxicity.

The comb-like ionic complexes resulting from stoichiometric or nearly stoichiometric coupling of polycarboxylic biopolymers with cationic surfactants are well-studied systems that are known to be stable and to adopt biphasic amphiphilic nanostructures. These complexes were first reported by Ponomarenko et al. ${ }^{20,21}$ for poly $(\alpha, \mathrm{L}$-glutamate) ionically coupled with alkyltrimethylammonium surfactants (nATMA) bearing alkyl chains with $n$ equal to $12,14,16$ and 18 carbon atoms. Later, similar complexes made from microbial poly( $\gamma$-glutamic acid) (PGGA) and $\operatorname{poly}(\beta, \mathrm{L}-\mathrm{malic}$ acid) with alkyltrimethylammonium and/or alkyltrimethylphosphonium surfactants were described. ${ }^{22-25}$ Also, ionic complexes of certain polyuronic acids (alginic, galacturonic, hyaluronic) with similar surfactants have been examined. ${ }^{26-28}$ In all cases, the surfactant-biopolymer complexes were able to self-assemble in 
the characteristic biphasic layered arrangement although displaying some structural differences depending on the chemical constitution of the two building blocks.

Alkyltrimethyl-onium soaps are compounds with a remarkable biocidal activity and therefore unsuitable for therapeutic applications implying cell internalization. Conversely, alkanoylcholine surfactants $(n \mathrm{ACh})$ are claimed to be harmless for living organisms since they have been proved to be readily hydrolyzed by butyrylcholine esterase generating common components of human metabolism. ${ }^{29}$ Alkanoylcholines are compounds closely related to naturally occurring phospholipids like lecithin that belongs to one of the bio-surfactants groups. They are recognized in pharmacology for their capacity to modify the blood pressure ${ }^{30}$ and to favor the adsorption of drugs from the gastrointestinal tract. ${ }^{31}$ They show also a good penetration through the Blood Brain Barrier (BBB) with therapeutic effects on cognitive-related illnesses such as Alzheimer disease. $^{32,33} n \mathrm{ACh}$ bearing long alkanoyl chains have been coupled to PGGA to produce ionic complexes ( $n \mathrm{ACh} \cdot \mathrm{PGGA})$ with structure and properties similar to those prepared from $n$ ATMA. $^{34}$ Nanoparticles of 50-100 nm diameter prepared from these complexes were able to load efficiently DOX although the release kinetics of the drug was slow with less than $10 \%$ released after 30 days. $^{35}$

Consequently, the combination of HyA and alkanoylcholines to form ionic complexes appears as an excellent approach toward the design of biocompatible systems for targeted drug delivery on tumoral cells. The simplicity of the preparation method, the outstanding bio-properties of the two components, and the amphiphilic biphasic arrangements that the complexes tend to adopt will make these systems highly promising in the drug delivery field. Here, we report the synthesis of new NPs made by the complexation of HyA and alkanoylcholines with alkyl chains made of $n$ carbon atoms $(12,14,16$ and 18) (Figure 1). A library of $n \mathrm{ACh} \cdot \mathrm{HyA}$ complexes has 
been synthesized and characterized in detail with special emphasis placed on the dependence of their nanostructure and properties on the length of the alkanoyl group. Nanoparticles were then prepared from some of these complexes, their cytotoxicity in vitro evaluated, and the loading and release of the anticancer drug doxorubicin preliminary examined.

a)
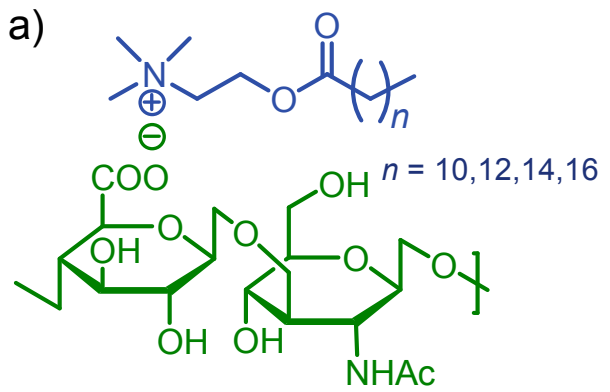

$n \mathrm{ACh} \cdot \mathrm{HyA}$ b)<smiles>CC(C)(C)CC=CCC(C)(C)CC(=O)OCC[N+](C)(C)C</smiles>

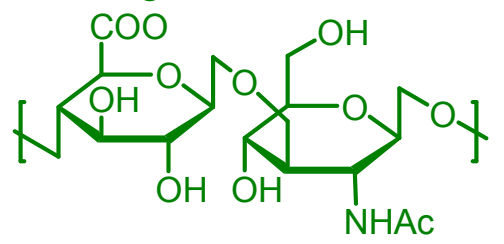

cis18ACh·HyA

Figure 1. Chemical structure of the ionic complexes made of HyA and choline esters of saturated (a) and unsaturated (b) fatty acids.

\section{EXPERIMENTAL}

Materials. The sodium salt of hyaluronic acid $(\mathrm{Na} \cdot \mathrm{HyA})$ with a weight-average molecular weight of about 50,000 $\mathrm{Da}$ used in this work was purchased from Enze Chemicals. Alkanoylcholine surfactants salts ( $n \mathrm{ACh} \cdot \mathrm{I}$ with even $n$ values ranging from 12 to 18 ) were synthesized as we have previously described. ${ }^{33}$ Doxorubicin $((7 S, 9 S)-7-[2 R, 4 S, 5 S, 6 S)$-4-amino5-hydroxy-6-methyloxan-2-yl] oxy-6,9,11-trihydroxy-9-(2-hydroxyacetyl)-4-methoxy-8,10dihydro-7H-tetracene-5,12-dione (DOX) was supplied by AKSci (Union City. CA, USA). Solvents were supplied from Panreac and used without further purification.

Measurements. FTIR spectra were recorded on a FTIR Perkin Elmer Frontier spectrophotometer within the $4000-600 \mathrm{~cm}^{-1}$ interval which was provided with a universal ATR 
sampling accessory for the examination of solid samples. ${ }^{1} \mathrm{H}$ and ${ }^{13} \mathrm{C}$ NMR spectra were recorded on a Bruker AMX-300 NMR instrument operating at 300.1 and $75.5 \mathrm{MHz}$, respectively, with samples dissolved in deuterated methanol $\left(\mathrm{CD}_{3} \mathrm{OD}\right)$ or chloroform $\left(\mathrm{CDCl}_{3}\right)$. Calorimetric measurements were performed with a Perkin-Elmer DSC 8000 differential scanning calorimeter (DSC) instrument calibrated with indium and zinc. Sample weights of about 2-5 mg were examined in a temperature range of -30 to $120{ }^{\circ} \mathrm{C}$ under a nitrogen atmosphere. Thermogravimetric analyses (TGA) were performed at a heating rate of $10{ }^{\circ} \mathrm{C} \cdot \mathrm{min}^{-1}$ between 30 to $600{ }^{\circ} \mathrm{C}$ under nitrogen on a Mettler-Toledo TGA/DSC 1 Star System thermobalance.

Polarizing optical microscopy (POM) images were obtained on an Olympus BX51 microscope equipped with a digital camera. For observation, several drops of a $5 \%(\mathrm{w} / \mathrm{v})$ solution of the $n \mathrm{ACh} \cdot \mathrm{HyA}$ complex in methanol were placed between two microscope cover slides and left to dry. Real-time X-ray diffraction in both WAXS and SAXS regions were performed using X-ray synchrotron radiation at the BL11 beamline (NCD, Non-Crystalline Diffraction) of ALBA in Cerdanyola del Vallès (Barcelona). Variable temperature experiments were performed at heating and cooling rates of $10^{\circ} \mathrm{C} \cdot \mathrm{min}^{-1}$. The employed radiation energy corresponded to a $0.10 \mathrm{~nm}$ wavelength, and spectra were calibrated with silver behenate (AgBh) and $\mathrm{Cr}_{2} \mathrm{O}_{3}$ for $\mathrm{SAXS}$ and WAXS, respectively. Transmission electron microscopy (TEM) of $n$ ACh $\cdot H y A$ complexes was carried out at the Physical Chemistry of Polymers center of the Max Planck Institute of Polymer Research (Germany) using a Tecnai F20 electron microscope operating at $200 \mathrm{kV}$. Specimens for observation were prepared by casting a solution of $n \mathrm{ACh} \cdot \mathrm{HyA}$ complexes in $\mathrm{MeOH}: \mathrm{BuOH}(4: 1)$ over a water surface, taking out pieces of the complex film with carbon coated grids, and finally staining them with aqueous $4 \%$ uranyl acetate. For NPs imaging, drops of the suspensions were 
placed onto carbon-coated grids and the adhered material washed with water and stained as before.

Dynamic light scattering (DLS) for particle hydrodynamic size measurement was performed with PSS NICOMP ${ }^{\mathrm{TM}}$ (Particle Sizing System, Inc. Santa Barbara, Calif., USA), and displayed values were the average of three readings. $\zeta$-potential measurements were performed with a ZetaSizer NS (Malvern Instruments, UK) with particles suspended in deionized water and displayed values were the average of twelve readings.

Complexes formation and decomposition in aqueous environment. $n \mathrm{ACh} \cdot \mathrm{HyA}$ complexes were prepared following the methodology used previously by us for coupling either PGGA or polyuronic acids with tetraalkylammonium salts bearing long linear alkyl chains, ${ }^{22,26}$ and more specifically for the preparation of $n \mathrm{ATMA} \cdot \mathrm{HyA}^{27}$ and $n \mathrm{ACh} \cdot \mathrm{PGGA}$ complexes. ${ }^{34}$ In brief, an aqueous solution of the $n \mathrm{ACh} \cdot \mathrm{I}$ was added dropwise to an aqueous solution of $\mathrm{Na} \cdot \mathrm{HyA}$ under stirring at a temperature between 25 and $70^{\circ} \mathrm{C}$ depending on the surfactant. The white precipitate appearing after several hours of stirring was isolated by centrifugation, repeatedly washed with water, and finally dried under vacuum for at least $48 \mathrm{~h}$.

The propensity of $n \mathrm{ACh} \cdot \mathrm{HyA}$ complexes to decompose by the action of water was evaluated using PBS at pH 7.4 and $37^{\circ} \mathrm{C}$ as incubation medium, both in the presence and in the absence of hyaluronidases. $n \mathrm{ACh} \cdot \mathrm{HyA}$ complexes with $n$ values of 12 and 18 were selected for this study to assess the effect of the alkyl chain length on the stability of the complexes. Films of the complexes with a thickness of $100-150 \mu \mathrm{m}$ were prepared by casting from a $10 \%(\mathrm{w} / \mathrm{w}) \mathrm{MeOH}$ solution at room temperature. Discs of $5 \mathrm{~mm}$ of diameter were cut from films and placed in sealed vials, immersed in the incubation medium, and stored at $37^{\circ} \mathrm{C}$ in a thermostated chamber. 
Discs were withdrawn at scheduled times, washed with distilled water, dried under vacuum at room temperature, and finally weighted and examined by FTIR spectroscopy.

Nanoparticles preparation and drug encapsulation and delivery. NPs made of 18ACh·HyA and $\operatorname{cis} 18 \mathrm{ACh} \cdot \mathrm{HyA}$ were prepared in aqueous media by ionotropic gelation avoiding thus the use of organic solvents. The procedure was essentially the same that was applied for the preparation of the complexes but in this case, surfactant to HyA ratios of 1:4 and 1:2 were used. NPs were formed in aqueous medium by nanoprecipitation upon dropwise addition of the $n \mathrm{ACh}$ salt solution to the HyA solution under gentle stirring. After leaving the mixture under stirring for $4 \mathrm{~h}$ further, it was dialyzed against water for $24 \mathrm{~h}$, and the clean NPs emulsion was then subjected to characterization

For drug encapsulation and delivery study, doxorubicin (DOX) was loaded in both films and NPs of complexes. DOX-loaded NPs were prepared as described above but using an aqueous solution of HyA that contained DOX at a concentration of $10 \%(w / w)$. DOX-loaded films were prepared from a solution of the complex in $\mathrm{MeOH}$ containing $10 \%(\mathrm{w} / \mathrm{w})$ of DOX that was placed in a petri dish and left to dry at room temperature. The release of the drug from films and NPs was followed by placing $5 \mathrm{mg}$ of the loaded material suspended in $2 \mathrm{~mL}$ of PBS inside a cellulose tube (cut-off $\mathrm{M}_{\mathrm{w}}$ 14,000) and left to dialyze under gentle stirring against $15 \mathrm{~mL}$ of PBS at $37^{\circ} \mathrm{C}$. Drug release was monitored by UV spectroscopy of the dialysate with calibration made with known amounts of free DOX (480 nm).

Cytotoxicity assays. The cytotoxicity of $n \mathrm{ACh} \cdot \mathrm{HyA}$ NPs was evaluated in vitro on raw 264.7 cell line. The murine macrophage cell line RAW 264.7 was cultured with $10 \%$ fetal bovine serum (FBS) in RPMI medium containing $100 \mathrm{U} \cdot \mathrm{mL}^{-1}$ of penicillin, $100 \mathrm{mg} \cdot \mathrm{mL}^{-1}$ of streptomycin (all from Gibco, Germany) in an incubator at $37^{\circ} \mathrm{C}$ with $5 \% \mathrm{CO}_{2}$. The RAW 264.7 
cells were seeded out in 24 -well plates (100,000 cells per well) 1 day before the experiment. On the day of the experiment, the cells were incubated in fresh RPMI medium to witch the nanoparticle dispersions was added at a concentration of $75 \mu \mathrm{g} \cdot \mathrm{mL}^{-1}$ and then incubated at $37{ }^{\circ} \mathrm{C}$ for different durations. After $4 \mathrm{~h}$ or $24 \mathrm{~h}$, the cells were detached using $0.25 \%$ Trypsin (Gibco), washed by centrifugation (7 min, $300 \mathrm{~g}$ ), and the pellet resuspended in PBS. The cell viability was measured by flow cytometry. The viability of the cells was quantified by staining the sample before measurement with the viability dye Zombie Aqua (BioLegend) according to the manufacturer protocol. The $405 \mathrm{~nm}$ laser was used for the excitation of the Zombie Aqua dye (emission: $512 \mathrm{~nm}$ ). Flow cytometry analysis was conducted on an Attune NxT (Invitrogen). The mean values and standard deviations were determined from biological duplicates.

\section{RESULTS AND DISCUSSION}

Synthesis and chemical characterization of $n \mathrm{ACh} \cdot \mathrm{HyA}$ complexes. The synthesis of $n \mathrm{ACh} \cdot \mathrm{I}$ (for $n=12,14,16,18$ and cis-18) surfactants carried out as previously reported. ${ }^{36}$ All the surfactants were obtained in good yields as white powders. The chemical constitution and purity of $n \mathrm{ACh} \cdot \mathrm{I}$ was assessed by ${ }^{1} \mathrm{H}$ and ${ }^{13} \mathrm{C}$ NMR spectroscopy (SI file, Figures $\mathrm{S} 1$ and S2).

$n \mathrm{ACh} \cdot \mathrm{HyA}$ complexes were obtained as white precipitates by the slow mixing of the aqueous solutions of HyA and surfactant at the minimum temperature required to dissolve the surfactant. Yields between 70 and $90 \%$ were attained by using a $0.01 \mathrm{M}$ concentration for the two solutions except in the case of $12 \mathrm{ACh} \cdot \mathrm{HyA}$, where it was raised to $0.02 \mathrm{M}$ for improving the yield which increased from $45 \%$ up to $70 \%$. The whole set of $n \mathrm{ACh} \cdot \mathrm{HyA}$ complexes showed the typical solubility behavior of polymers with a strong amphiphilic character, i.e. they were soluble in methanol but insoluble in neither water nor chloroform. 
Table 1. Results for the preparation of $n \mathrm{ACh} \cdot \mathrm{HyA}$ complexes

\begin{tabular}{|c|c|c|c|c|c|}
\hline \multirow{2}{*}{ Complex } & \multicolumn{2}{|c|}{ Mixing condition } & \multirow{2}{*}{ Yield (\%) } & \multirow{2}{*}{ Color } & \multirow{2}{*}{ Composition $^{\mathrm{c}}$} \\
\hline & $c(\mathrm{M})^{\mathrm{a}}$ & $T\left({ }^{\circ} \mathrm{C}\right)^{\mathrm{b}}$ & & & \\
\hline 12ACh $\cdot \mathrm{HyA}$ & 0.02 & 45 & 70 & white & $1.1: 1.0$ \\
\hline 14ACh $\cdot$ HyA & 0.01 & 55 & 77 & white & $1.2: 1.0$ \\
\hline 16ACh $\cdot \mathrm{HyA}$ & 0.01 & 65 & 85 & white & $1.3: 1.0$ \\
\hline 18ACh $\cdot \mathrm{HyA}$ & 0.01 & 70 & 90 & white & $1.3: 1.0$ \\
\hline cis $18 \mathrm{ACh} \cdot \mathrm{HyA}$ & 0.01 & 40 & 84 & white & $1.7: 1.0$ \\
\hline
\end{tabular}

\footnotetext{
${ }^{\mathrm{a}}$ Concentration of the two solutions mixed to form the complex.

${ }^{\mathrm{b}}$ Temperature selected according to the surfactant solubility in water.

${ }^{c}$ Molar ratio of $n \mathrm{ACh}$ to HyA in the complex
}

The chemical characterization of $n \mathrm{ACh} \cdot \mathrm{HyA}$ complexes was performed by both FTIR and ${ }^{1} \mathrm{H}$ NMR spectroscopies. The FTIR spectra recorded for the whole set of $n \mathrm{ACh} \cdot \mathrm{HyA}$ are compared in Figure 2 together with those of $\mathrm{Na} \cdot \mathrm{HyA}$ and 18ACh·I. As expected, the spectra of all complexes contain the bands characteristic of the two components with intensities according to composition. Thus, the characteristic broad adsorption of hyaluronic acid at $3300 \mathrm{~cm}^{-1}$ that arises from $\mathrm{N}-\mathrm{H}$ and $\mathrm{O}-\mathrm{H}$ stretching vibrations appears with an intensity that decays with the increasing value of $n$ and that arrives to be almost imperceptible for $n 16$ and 18. A similar behavior is observed for the $1030 \mathrm{~cm}^{-1}$ band which is characteristic of the glycosidic C-O-C group, ${ }^{37,38}$ as well as for the $\sim 1650 \mathrm{~cm}^{-1}$ group of bands attributed to the different stretching modes of the $\mathrm{N}$ $\mathrm{CO}$ structure present in the acetamide group of HyA. On the other hand, the bands typical of $n \mathrm{ACh} \cdot \mathrm{I}$ surfactants at 1738 and $1165 \mathrm{~cm}^{-1}\left(\mathrm{C}=\mathrm{O}\right.$ and $\mathrm{C}-\mathrm{O}$ stretching), $950 \mathrm{~cm}^{-1}$ (C-C-stretching vibrations) and $1470,725 \mathrm{~cm}^{-1}\left(\mathrm{CH}_{2}\right.$ scissoring and rocking vibrations, respectively) are visible in every spectrum and their intensities increasing with the value of $n$. The spectrum of cis- 
$18 \mathrm{ACh} \cdot \mathrm{HyA}$ fits well in the general trend with the addition of the weak band at $\sim 3005 \mathrm{~cm}^{-1}$ that arises from the $\mathrm{C}-\mathrm{H}$ stretching vibration associated to the double bond.

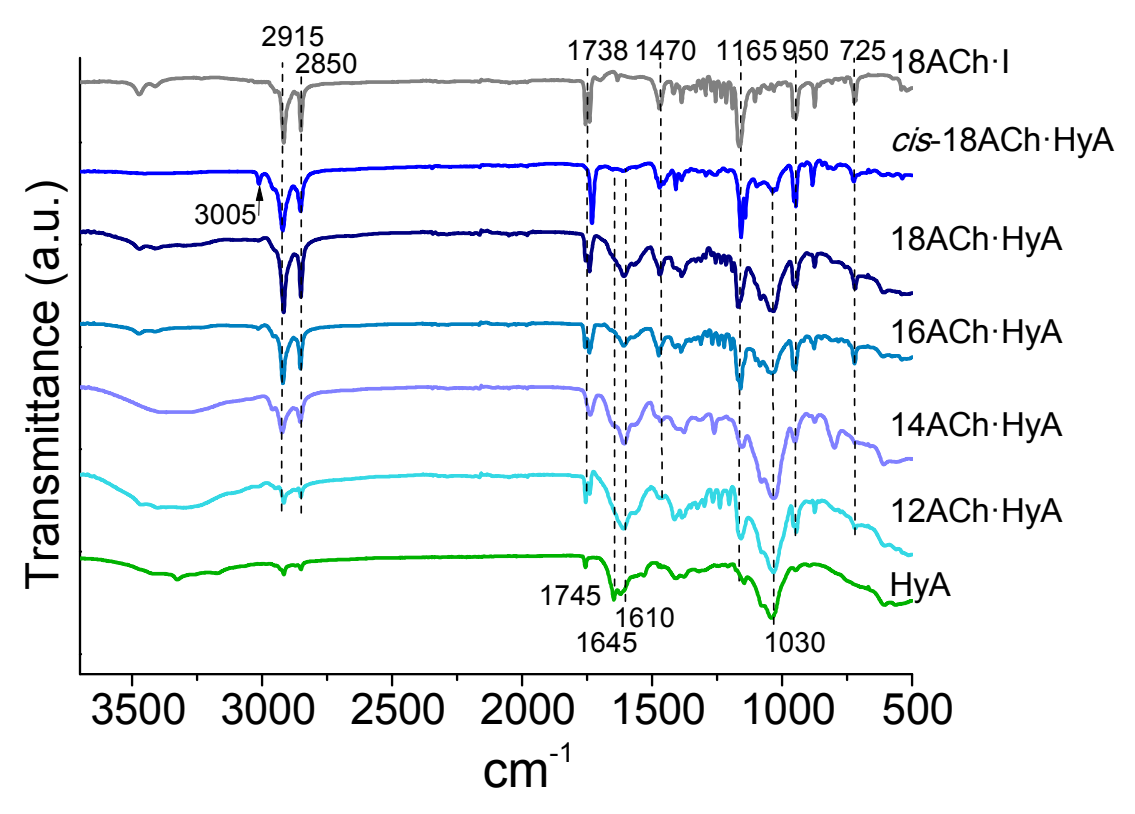

Figure 2. FTIR spectra of the whole set of $n \mathrm{ACh} \cdot \mathrm{HyA}$ complexes. The spectra of $\mathrm{Na} \cdot \mathrm{HyA}$ and $18 \mathrm{ACh} \cdot \mathrm{I}$ are included for reference.

The NMR spectroscopy was used to confirm the chemical structure of the $n \mathrm{ACh} \cdot \mathrm{HyA}$ complexes (SI file, Figures S3 and S4). The ${ }^{1} \mathrm{H}$ NMR spectra of $18 \mathrm{ACh} \cdot \mathrm{HyA}$ and cis $18 \mathrm{ACh} \cdot \mathrm{HyA}$ are shown in Figure 3 to illustrate the differences observed between saturated and unsaturated complexes. The later contains all the signals observed for the former in addition to two new signals characteristic of the double bond $\left({ }^{9,10} \mathrm{CH}=\right.$ at $5.2-5.6 \mathrm{ppm}$ and ${ }^{8,11} \mathrm{CH}_{2}-\mathrm{CH}=$, at 1.8-2.2 ppm). The contents of $n \mathrm{ACh}$ and HyA in the complexes were determined by ${ }^{1} \mathrm{H}$ NMR on the basis of the area ratio of selected signals arising from HyA and from the surfactant counterparts. Broadening and partial overlapping of signals prevented, however, a reliable area quantification. The areas of the inner methylenes $\left({ }^{3-17} \mathrm{CH}_{2}\right.$, at $\left.1.0-1.7 \mathrm{ppm}\right)$ and the $\mathrm{CO}-\mathrm{CH}_{2}$ 
methylene $\left({ }^{2} \mathrm{CH}_{2}\right.$, at $\left.2.4 \mathrm{ppm}\right)$ or the end methyl $\left({ }^{18} \mathrm{CH}_{3}\right.$, at $\left.0.85 \mathrm{ppm}\right)$ signals of $n \mathrm{ACh}$ were compared to the signal due to the methyl protons of the acetamide group of HyA $\left(\mathrm{CH}_{3}\right.$, at 2.0 ppm). Spectra were acquired at room temperature and also at $60{ }^{\circ} \mathrm{C}$ in order to minimize effects due to restricted mobility and loss of signal of the polysaccharide chain. The results obtained by these calculations revealed that $n \mathrm{ACh} \cdot \mathrm{HyA}$ complexes have a composition with $n \mathrm{ACh}$ to HyA ratios between of 1.0 and 1.3 for the saturated compounds and around 1.7 for the unsaturated cis18ACh·HyA (Table 1). A detailed account of the measurements carried out and approximations made for quantification is given in the SI file (Table S1)

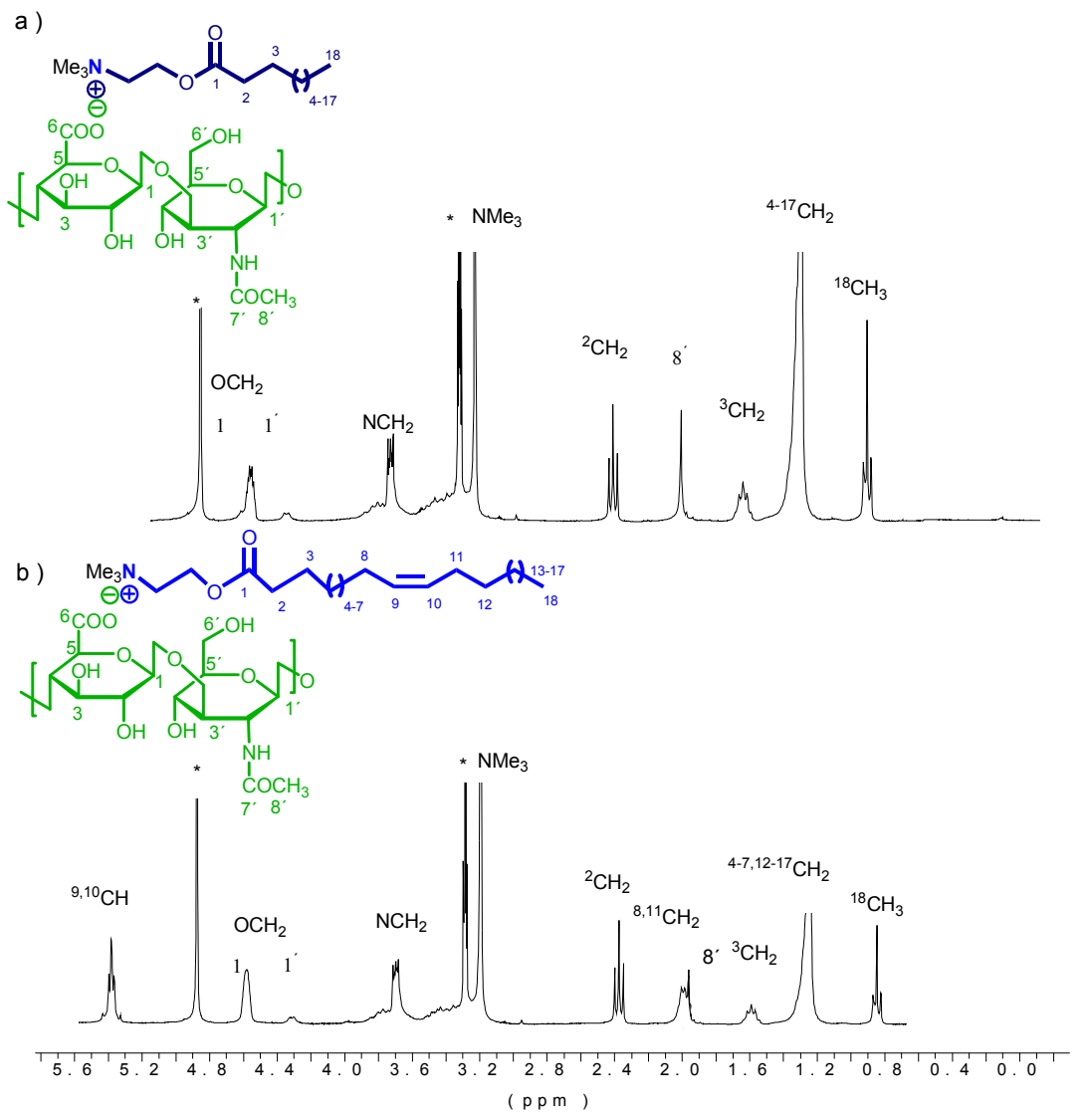

Figure 3. ${ }^{1} \mathrm{H}$ NMR spectra of $18 \mathrm{ACh} \cdot \mathrm{HyA}$ (a) and cis $18 \mathrm{ACh} \cdot \mathrm{HyA}$ (b) complexes recorded in $\mathrm{CD}_{3} \mathrm{OD}$. 
Thermal properties of $\boldsymbol{n A C h} \cdot \mathbf{H y A}$ complexes. The thermal behavior of $n \mathrm{ACh} \cdot \mathrm{HyA}$ complexes was examined by TGA and DSC, and data obtained by these analyses are summarized in Table 2. The TGA traces recorded from all the samples, as well as their derivatives curves, are shown in Figure 4. The thermal decomposition started to be detectable at $190-210^{\circ} \mathrm{C}$ revealing that both $n \mathrm{ACh}$ and HyA, which have onset decomposition temperatures at ca. $200-210^{\circ} \mathrm{C},{ }^{40,41}$ retained their thermal stability after complexation. The first derivative of the TGA curves (Figure 4b) shows that saturated $n \mathrm{ACh} \cdot \mathrm{HyA}$ complexes decomposed through a process that involves two steps, the first one at a temperature between $220-226^{\circ} \mathrm{C}$ and the second one between $255-290{ }^{\circ} \mathrm{C}$. All these complexes left a residual weight of $12-14 \%$ after being heated at $600{ }^{\circ} \mathrm{C}$. ${ }^{\max } T_{d}$ for the first step were within the $220-226{ }^{\circ} \mathrm{C}$ range, which are values close to the ${ }^{\max } T_{d}$ of HyA and $n \mathrm{ACh}$. Conversely, ${ }^{\max } T_{d}$ of the second step were well above 250 ${ }^{\circ} \mathrm{C}$ and increased steadily with $n$, suggesting that decomposition of the alkanoyl chain of the surfactant must be involved in this step.

Table 2. Thermal parameters of $n \mathrm{ACh} \cdot \mathrm{HyA}$

\begin{tabular}{|c|c|c|c|c|c|c|c|c|c|c|}
\hline \multirow[t]{3}{*}{ Complex } & \multirow{2}{*}{\multicolumn{3}{|c|}{$\mathrm{TGA}^{\mathrm{a}}$}} & \multicolumn{7}{|c|}{$\mathrm{DSC}^{\mathrm{b}}$} \\
\hline & & & & \multicolumn{3}{|c|}{$1^{\text {st }}$ Heating } & \multicolumn{2}{|c|}{ Cooling } & \multicolumn{2}{|c|}{$2^{\text {nd }}$ Heating } \\
\hline & $\begin{array}{l}{ }^{\circ} T_{\mathrm{d}} \\
\left({ }^{\circ} \mathrm{C}\right)\end{array}$ & $\begin{array}{l}{ }^{\max } T_{\mathrm{d}} \\
\left({ }^{\circ} \mathrm{C}\right)\end{array}$ & $\begin{array}{l}W \\
(\%)\end{array}$ & $\begin{array}{c}T_{m} \\
\left({ }^{\circ} \mathrm{C}\right)\end{array}$ & $\begin{array}{c}\Delta H_{m} \\
\left(\mathrm{Kcal} \cdot \mathrm{mol}^{-1}\right)\end{array}$ & $n_{\mathrm{c}}$ & $\begin{array}{c}T_{c} \\
\left({ }^{\circ} \mathrm{C}\right)\end{array}$ & $\begin{array}{c}\Delta H_{c} \\
\left(\mathrm{Kcal}^{\left.-\mathrm{mol}^{-1}\right)}\right)\end{array}$ & $\begin{array}{c}T_{m} \\
\left({ }^{\circ} \mathrm{C}\right)\end{array}$ & $\begin{array}{c}\Delta H_{m} \\
\left(\mathrm{Kcal} \cdot \mathrm{mol}^{-1}\right)\end{array}$ \\
\hline 12ACh·HyA & 200 & $220 / 255$ & 14 & - & - & - & & & - & - \\
\hline 14ACh $\cdot \mathrm{HyA}$ & 205 & $222 / 265$ & 14 & 50 & 0.8 & 1 & - & - & - & - \\
\hline 16ACh $\cdot \mathrm{HyA}$ & 212 & $226 / 272$ & 14 & 55 & 1.9 & 3 & - & - & - & - \\
\hline 18ACh $\cdot \mathrm{HyA}$ & 216 & $226 / 290$ & 12 & 65 & 3.9 & 5 & 49 & -2.2 & 56 & 2.0 \\
\hline cis $18 \mathrm{ACh} \cdot \mathrm{HyA}$ & 194 & $211 / 274 / 334$ & 11 & - & - & - & - & - & - & - \\
\hline $18 \mathrm{ACh} \cdot \mathrm{I}^{\mathrm{c}}$ & 209 & $225 / 322$ & 0 & & & & & & & \\
\hline НyА & 200 & 228 & 35 & - & - & - & - & - & - & - \\
\hline
\end{tabular}

${ }^{\text {a } ~} T_{\mathrm{d}}$ onset for $5 \%$ of weight loss and ${ }^{\max } T_{\mathrm{d}}$ maximum rate decomposition temperatures. $W$ : remaining weight at $600{ }^{\circ} \mathrm{C}$.

${ }^{\mathrm{b}}$ Data obtained from DSC traces; $T_{\mathrm{m}}$ and $T_{\mathrm{c}}$ : Melting and crystallization temperatures $\left({ }^{\circ} \mathrm{C}\right) ; \Delta H_{\mathrm{m}}$ and $\Delta H_{\mathrm{c}}$ : melting and crystallization enthalpies. $n_{\mathrm{c}}$ : calculated average number of crystallized methylenes. ${ }^{\mathrm{c}}$ Data taken from reference 36. 
The TGA behavior observed for the $n \mathrm{ACh} \cdot \mathrm{HyA}$ series follows the behavior reported for both $n \mathrm{ACh} \cdot \mathrm{PGGA}^{34}$ and $n \mathrm{ATMA} \cdot \mathrm{HyA}^{27}$ series suggesting that a similar thermal decomposition mechanism pattern could be shared by the three families of complexes. At difference to what happens with PGGA, whose thermal decomposition has been studied in details, ${ }^{39,40}$ the decomposition of HyA is more complex and not as well characterized. ${ }^{41,42}$ Additional TGA assays including the analysis of HyA and $n \mathrm{ACh}$ would be needed to fully understand the thermal degradation mechanism of the $n \mathrm{ACh} \cdot \mathrm{HyA}$ complexes.
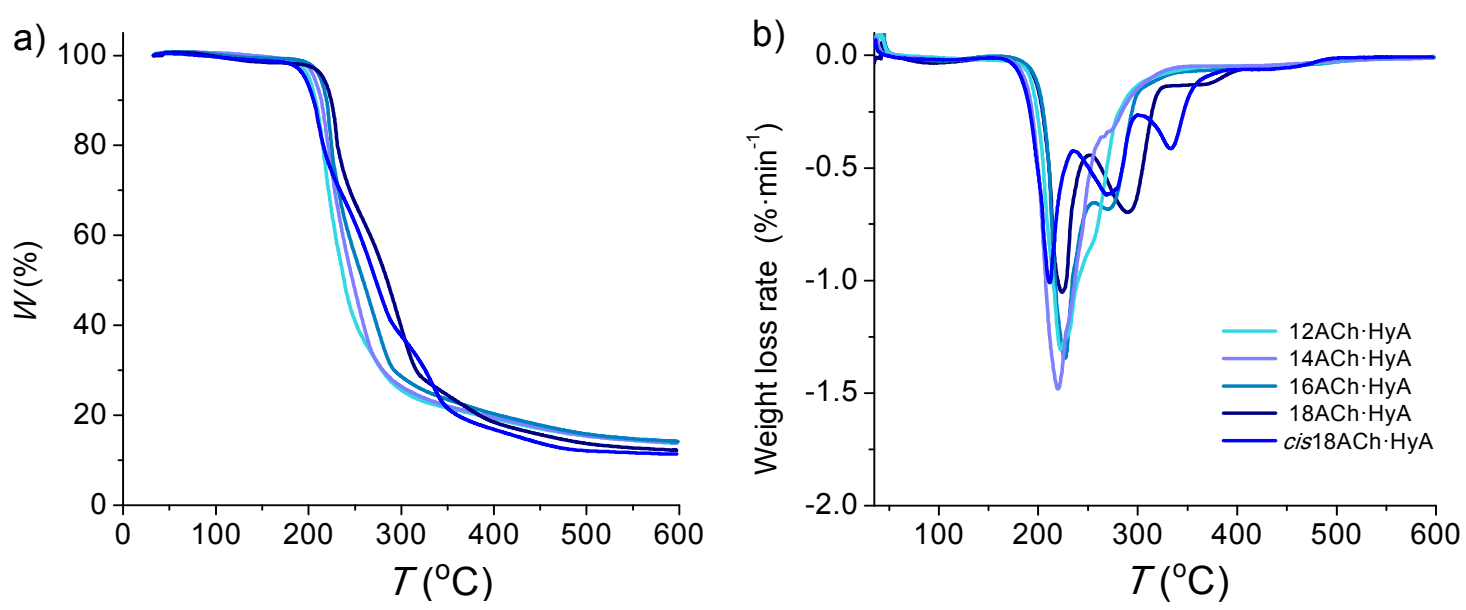

Figure 4. Comparison of the TGA traces for the whole set of $n \mathrm{ACh} \cdot \mathrm{HyA}$ complexes (a) and their derivatives curves (b).

Results for cis $18 \mathrm{ACh} \cdot \mathrm{HyA}$ were found to deviate significantly from the pattern observed for the $n \mathrm{ACh} \cdot \mathrm{HyA}$ series, which may be attributed to the presence of the double bond in the hydrocarbon tail of the oleyl-derived surfactant. In this case, the TGA derivative curve shows an additional third decomposition step in the $330-340{ }^{\circ} \mathrm{C}$ range which is the consequence of the higher heat resistance that should be expected for the double bond. 
The DSC traces for the whole set of complexes are compared in Figure 5a showing that saturated complexes with $n \geq 14$ contain endothermic peaks at temperatures steadily increasing from $50{ }^{\circ} \mathrm{C}$ up to $65^{\circ} \mathrm{C}$ with the value of $n$. According to the thermal behavior of comb-like ionic polymer complexes, ${ }^{20-24}$ the observed endothermic peaks are associated with the melting of the paraffinic phase of the complex composed of the alkyl chains of the surfactant. The enthalpy of these peaks diminished from 3.9 to $0.8 \mathrm{Kcal} \cdot \mathrm{mol}^{-1}$ for $n$ decreasing from 18 to 14 indicating that, as expected, crystallinity decreased with the length of the alkanoyl chain length. It is noticeable that these melting enthalpy values are much lower than those reported for $n \mathrm{ACh} \cdot \mathrm{PGGA}{ }^{34}$ (values ranging from 7 to $4 \mathrm{kcal} \cdot \mathrm{mol}^{-1}$ ) revealing that HyA is more effective than PGGA in disturbing the molecular arrangement required by the alkanoyl chain to crystallize within the complex structure. On the other hand, the enthalpy value observed here for $18 \mathrm{ACh} \cdot \mathrm{HyA}$ is significantly larger than that reported for $18 \mathrm{ATMA} \cdot \mathrm{HyA}^{27}\left(1.7 \mathrm{Kcal} \cdot \mathrm{mol}^{-1}\right)$ indicating that the flexible ester bond of the alkanoylcholine acts as a flexible spacer between the polysaccharide and the polymethylene chain favoring its accommodation into the crystal lattice of the paraffinic phase. Upon cooling from $120^{\circ} \mathrm{C}$, only $18 \mathrm{ACh} \cdot \mathrm{HyA}$ was able to crystallize confirming the dependence of crystallinity on $n$ (Figure 5b). As one can expect, the cis18ACh·HyA complex did not show any sign of melting or crystallization due to the presence of a double bond in a cis configuration hindering the crystal packing of the alkenoyl chains. Melting temperatures and enthalpies measured along the heating-cooling cycles for the whole set of complexes are given in Table 2 . 

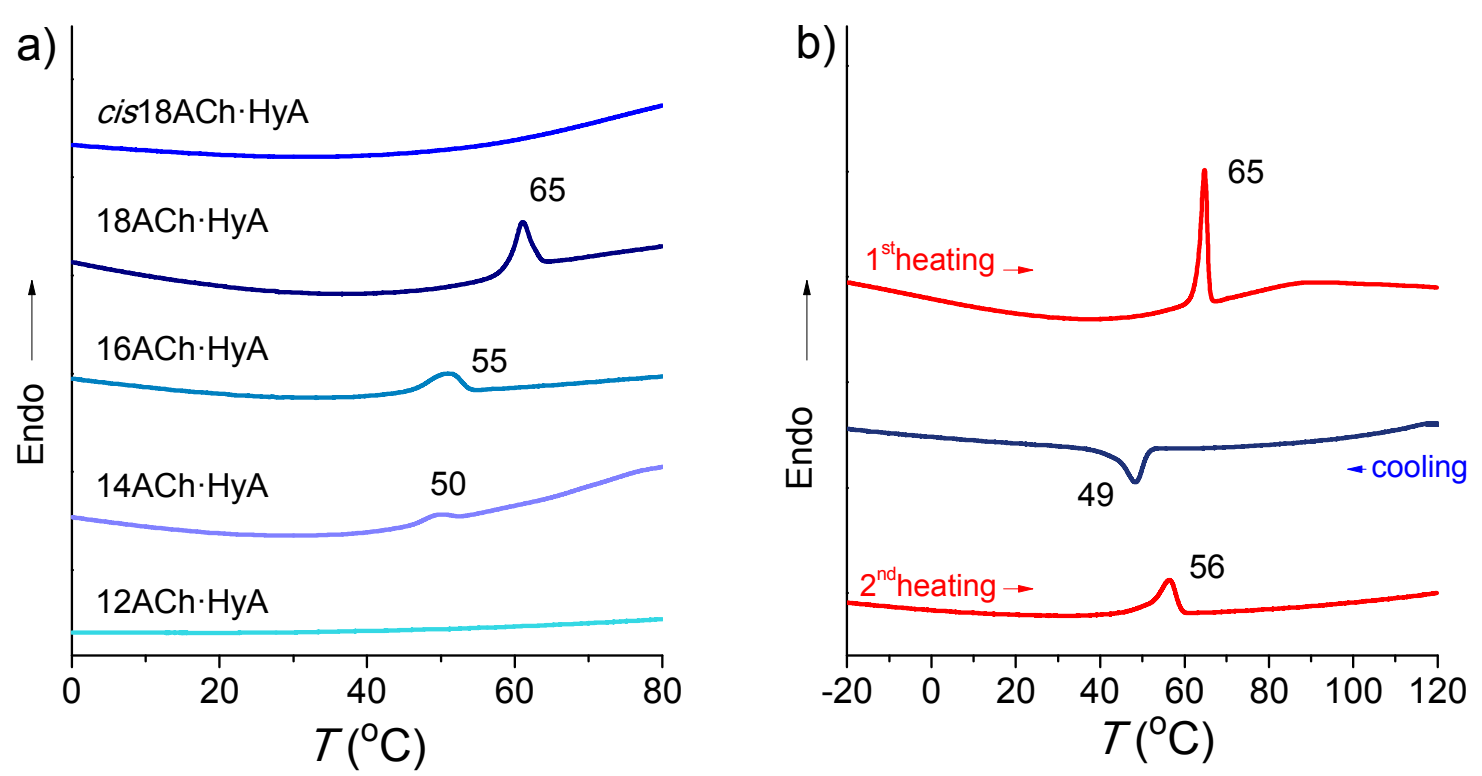

Figure 5. a) Heating DSC traces of the $n \mathrm{ACh} \cdot \mathrm{HyA}$ complexes and b) Heating-cooling DSC traces for $18 \mathrm{ACh} \cdot \mathrm{HyA}$.

Melting enthalpy may be used for calculating the number of carbons that are crystallized in the alkyl chain of each complex. ${ }^{43}$ Plotting $\Delta H_{m}$ against $n$ (Figure 6) results in the linear equation $\Delta H_{\mathrm{m}}=\Delta H_{\mathrm{end}}+n k$, where $\Delta H_{\mathrm{end}}$ and $k$ are constants reflecting the contribution made to the heat of fusion by the methyl end group and each methylene added to the alkyl chain, respectively. A slope $(k)$ of $0.78 \mathrm{Kcal} \cdot \mathrm{mol}^{-1} \mathrm{CH}_{2}^{-1}$ was found for the first heating, which is in good accordance with the slope of $0.8 \mathrm{Kcal} \cdot \mathrm{mol}^{-1} \mathrm{CH}_{2}^{-1}$ found for analogous complexes made of PGGA and alkanoylcholines. ${ }^{34}$ In agreement with the fusion enthalpy values reported for the crystal lattice adopted by the paraffinic phase associated to comb-like polymers, ${ }^{22,44}$ the $k$ value found here suggests that the polymethylene chains of $n \mathrm{ACh} \cdot \mathrm{HyA}$ complexes must be packed in a pseudohexagonal structure. The minimum number of methylenes $\left(n_{\mathrm{m}}\right)$ in the chain required for crystallization may be estimated by taking $\Delta H_{\mathrm{m}}=0$ in the $\Delta H_{\mathrm{m}} v s n$ plot, and the average number of methylenes $\left(n_{\mathrm{c}}\right)$ that are crystallized in one chain is given by $n-n_{\mathrm{m}}$. The resulting values for 
pristine complexes samples are given in Table 3 showing that the percentage of carbons crystallized in the alkanoyl chain decreased with its length, to the point that no crystallization was perceived for $12 \mathrm{ACh} \cdot \mathrm{HyA}$.

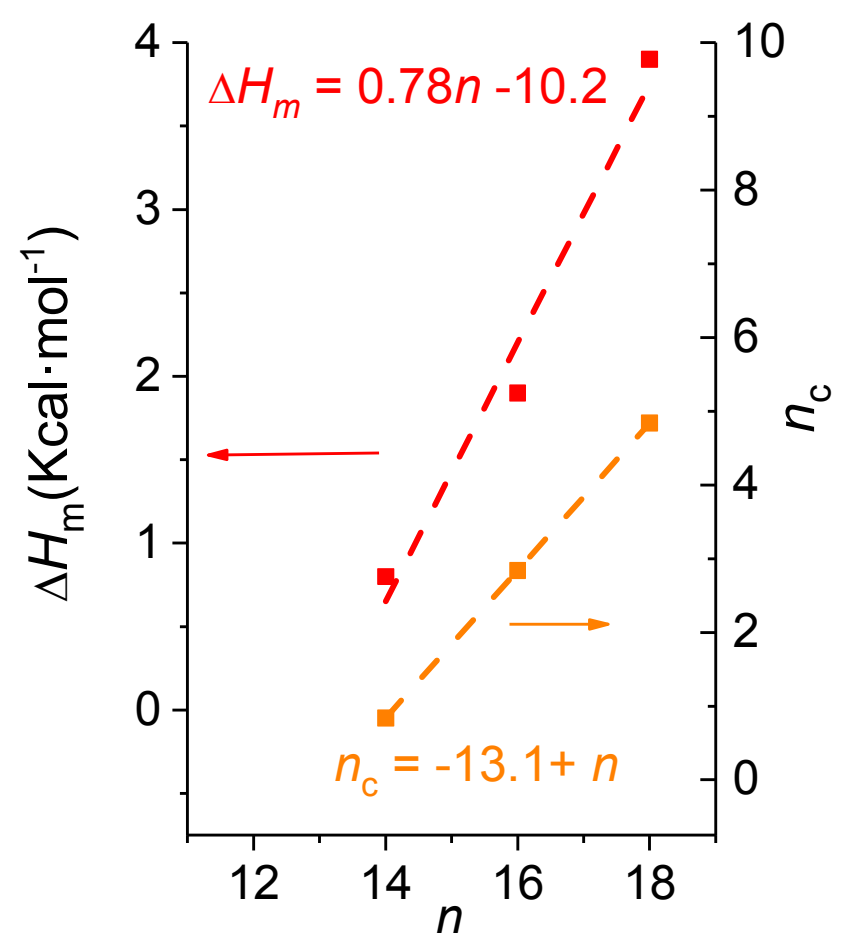

Figure 6. Melting enthalpy (left), and number of crystallized methylenes (right) against the number of carbons contained in the alkanoyl chain of nACh·HyA complexes.

Structure of $\boldsymbol{n} \mathbf{A C h} \cdot \mathbf{H y A}$ complexes. The structure of $n \mathrm{ACh} \cdot \mathrm{HyA}$ including both crystallinity and mesoscopic order was studied by XRD recorded simultaneously at both small and wide angles (SAXS and WAXS). The profiles recorded in the SAXS region displayed a sharp peak within the 3.9-4.7 $\mathrm{nm}$ range with a spacing that steadily moved upwards (higher spacing) with the increasing length of the alkanoyl chain (Figure 7a). According to other similar comb-like ionic polymer complexes made of either PGGA or HyA, this spacing is associated to the periodical distance $\left(L_{o}\right)$ of a biphasic layered structure in which the polysaccharide and the 
surfactant phases are alternating regularly. ${ }^{22,27,28,34}$ In Figure 8 the $L_{o}$ distances in $n \mathrm{ACh} \cdot \mathrm{HyA}$ complexes are represented as a function of $n$ and are compared with those reported for $n \mathrm{ACh} \cdot \mathrm{PGGA}$. In both cases, an almost linear fitting was attained with a similar slope of 0.12 $\mathrm{nm} \cdot \mathrm{CH}_{2}{ }^{-1}$, but with a significant increase in the periodical distance when the polypeptide was replaced by the polysaccharide. The observed slope corresponds approximately to an increase of half of the C-C-C backbone projection height per additional methylene unit. The expansion observed in the value of $L_{\mathrm{o}}$ for $n=0$ is fully related to the difference in the contour length of these two biopolymers.

a)

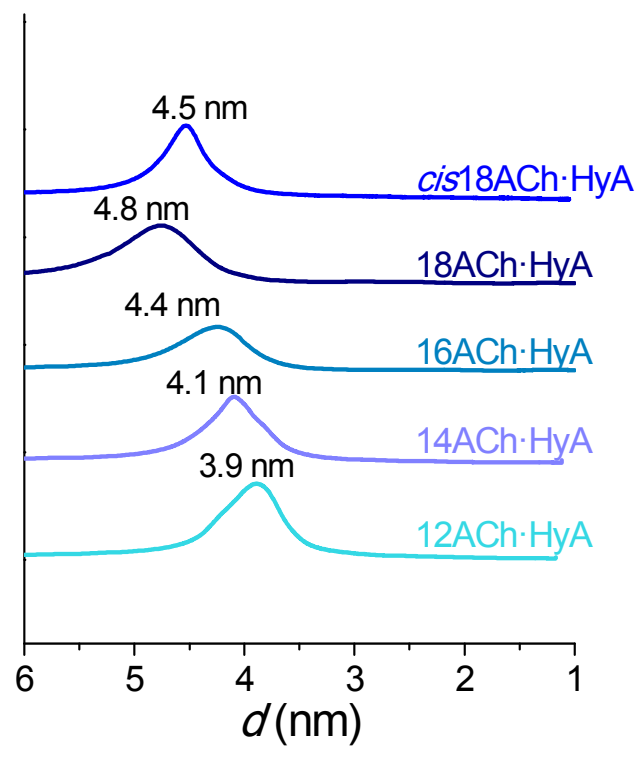

b)

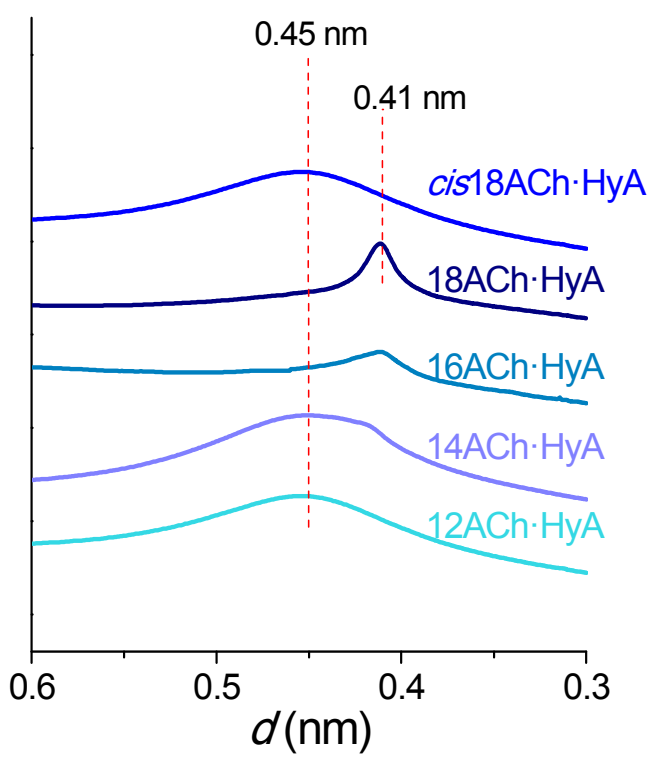

Figure 7. XRD profiles of $n \mathrm{ACh} \cdot \mathrm{HyA}$ recorded at room temperature in the SAXS (a) and WAXS regions (b).

The occurrence of the biphasic arrangement inferred from SAXS results was firmly supported by TEM results. Electron micrographs taken from films of the $18 \mathrm{ACh} \cdot \mathrm{HyA}$ prepared by casting on water showed clearly a striated structure corresponding to a layered structure with a 
periodicity that, as measured by optical diffraction, coincided with that defined by SAXS of this complex (Figure S5 in the SI file).

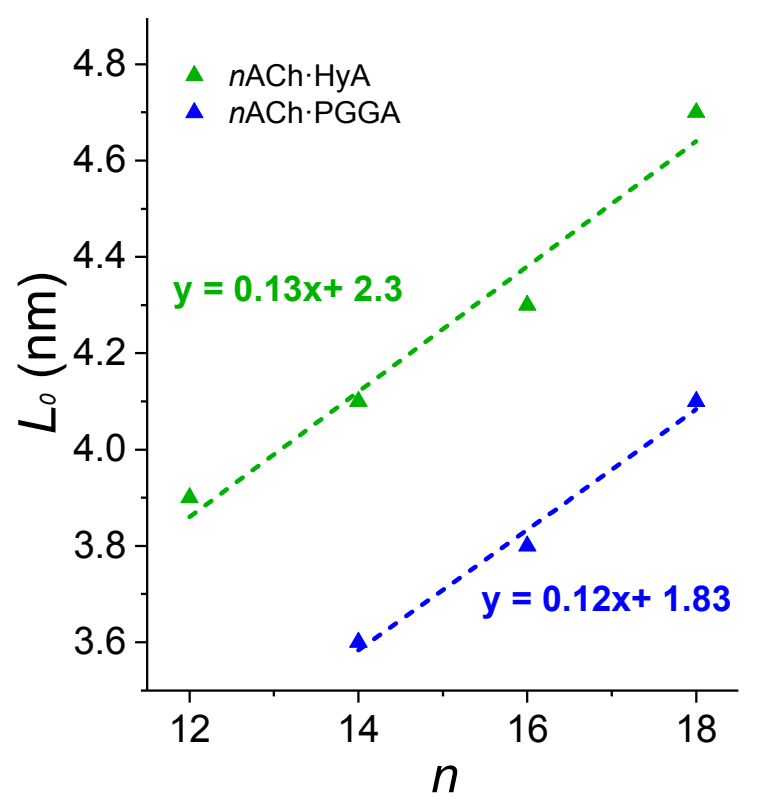

Figure 8. Plot of $L_{\mathrm{o}}$ against $n$ for $n \mathrm{ACh} \cdot \mathrm{HyA}$ and $n \mathrm{ACh} \cdot \mathrm{PGGA}$ complexes. Values for the latter have been taken from reference 34 .

The X-ray scattering recorded in the WAXS region (Figure 7b) provided a clear indication of the order attained in the paraffinic phase in nACh·HyA complexes. The results obtained are in full agreement with those obtained by DSC. Complexes with $n=16$ and 18 displayed a welldistinct peak at 0.41-0.42 nm which is characteristic of a crystalline state. On the contrary, the WAXS profiles recorded from both $12 \mathrm{ACh} \cdot \mathrm{HyA}$ and $\operatorname{cis} 18 \mathrm{ACh} \cdot \mathrm{HyA}$ showed a broad peak at $0.45 \mathrm{~nm}$ indicating that the alkanoyl chain remained uncrystallised in these complexes, in the former because the polymethylene chain is too short and in the latter because of the disturbing presence of the double bond in a cis-configuration. The profile recorded from $14 \mathrm{ACh} \cdot \mathrm{HyA}$ is predominantly amorphous but showed a small shoulder at $0.41 \mathrm{~nm}$ indicative of the presence of a 
minor fraction of crystallized material. According to the degree of order attained by the paraffinic phase, either a semicrystalline or a liquid-crystal state is adopted by the complex, which can be characterized by POM. Optical micrographs displaying the "batonnet" texture suggestive of the presence of a Smectic-A phase for $12 \mathrm{ACh} \cdot \mathrm{HyA}$, and the spherulitic morphology typical of semicrystalline polymers for 18ACh·HyA are shown in Figure S6 in the SI file.

Temperature effects on the structure of $\boldsymbol{n} \mathbf{A C h} \cdot \mathbf{H y A}$. To evaluate the effect of heating on the structure of the $n \mathrm{ACh} \cdot \mathrm{HyA}$ complexes, they were examined by real-time X-ray diffraction at variable temperatures over the $10-120{ }^{\circ} \mathrm{C}$ interval using synchrotron radiation. Data obtained from this study are collected in Table 3. The SAXS and WAXS profiles recorded along the applied heating-cooling cycle are displayed in Figures 9 and 10 for representative examples $(18 \mathrm{ACh} \cdot \mathrm{HyA}$ and $\operatorname{cis} 18 \mathrm{ACh} \cdot \mathrm{HyA})$, and the profiles for all the other complexes are provided in the SI file (Figures S7 and S8).

The changes observed in the scattering profiles of $18 \mathrm{ACh} \cdot \mathrm{HyA}$ produced in the WAXS region (Figure 9) are in full agreement with the melting-crystallization process taking place in this complex at temperatures between 50 and $70^{\circ} \mathrm{C}$. The sharp peak at $0.41 \mathrm{~nm}$ disappeared at $\sim 60$ ${ }^{\circ} \mathrm{C}$ and a broad peak at 0.45 appeared instead. This change is indicative of melting of the paraffinic lattice into a disordered structure in which chains are separated by an average distance of $0.45 \mathrm{~nm}$. During cooling, the $0.41 \mathrm{~nm}$ reappeared at around $50{ }^{\circ} \mathrm{C}$ to melt at $56{ }^{\circ} \mathrm{C}$ after reheating, a result that brings into evidence the reversibility of the melting-crystallization process in this complex. On the contrary, the WAXS profile of cis $18 \mathrm{ACh} \cdot \mathrm{HyA}$ barely changed along the heating-cooling cycle as it should be expected for a disordered phase. The changes observed during heating for the other complexes fit well in one of these two patterns depending on the 
degree of order attained by the alkanoyl chain in each case. During cooling none of the complexes showed a recovery of the 0.41 peak so that reversibility seems to be unique of the 18ACh·HyA complex.

Table 3. X-ray diffraction data of $n$ ATMP·PGGA complexes

\begin{tabular}{|c|c|c|c|c|c|c|}
\hline \multirow{2}{*}{ Complex } & \multicolumn{3}{|c|}{ SAXS } & \multicolumn{3}{|c|}{ WAXS } \\
\hline & $L_{0}{ }^{10^{\circ} \mathrm{C}}$ & $L_{0}{ }^{120^{\circ} \mathrm{C}}$ & $L_{0}{ }^{10^{\circ} \mathrm{C}}$ & $d_{100}{ }^{10^{\circ} \mathrm{C}}$ & $d_{100}{ }^{120^{\circ} \mathrm{C}}$ & $d_{100}{ }^{10^{\circ} \mathrm{C}}$ \\
\hline 12ACh.HyA & 3.9 & 3.7 & 3.8 & 0.45 & 0.45 & 0.45 \\
\hline 14ACh.HyA & 4.1 & 3.8 & 3.8 & $0.45(0.41)$ & 0.45 & 0.45 \\
\hline 16ACh.HyA & 4.3 & 4.4 & 4.2 & 0.41 & 0.45 & 0.45 \\
\hline 18ACh $\cdot \mathrm{HyA}$ & 4.7 & 4.8 & 4.7 & 0.41 & 0.45 & 0.41 \\
\hline cis18ACh $\cdot \mathrm{HyA}$ & 4.5 & 4.5 & 4.4 & 0.45 & 0.45 & 0.45 \\
\hline
\end{tabular}



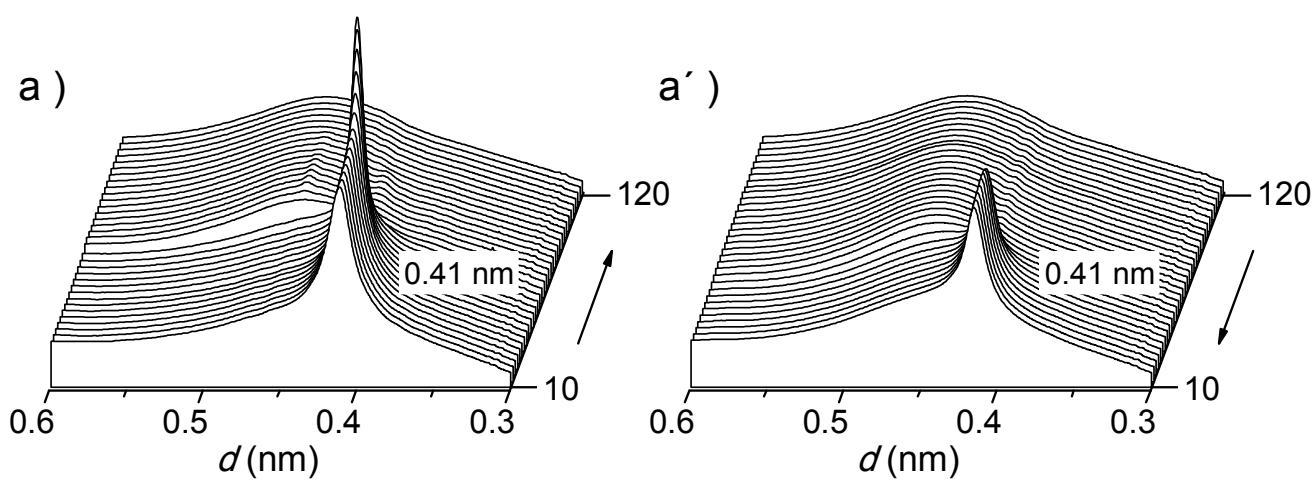

b )

$\left.b^{\prime}\right)$
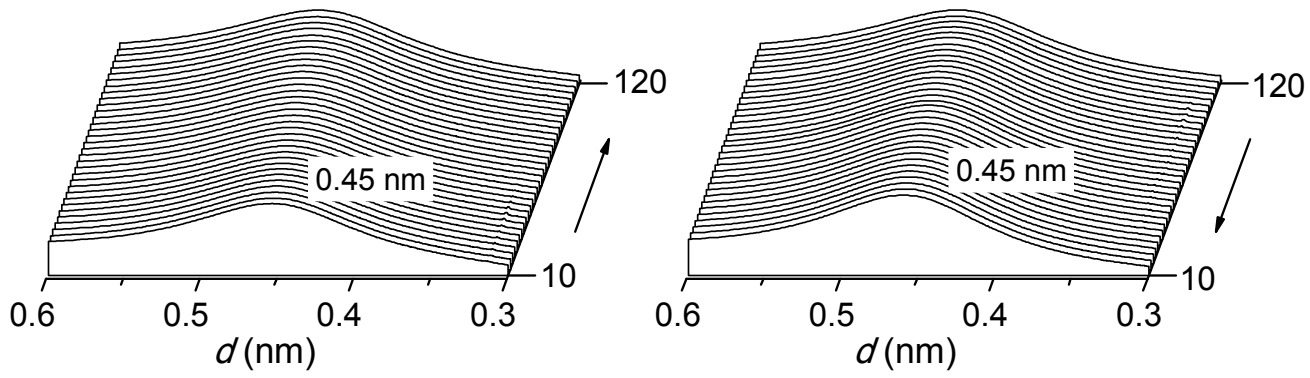

Figure 9. WAXS profiles of 18ACh $\cdot \mathrm{HyA}($ top) and cis18ACh $\cdot \mathrm{HyA}$ (bottom) at heating (a and b) and cooling $\left(\mathrm{a}^{6}\right.$ and $\left.\mathrm{b}^{\prime}\right)$ along the $10-120^{\circ} \mathrm{C}$ range

The SAXS profiles produced by $18 \mathrm{ACh} \cdot \mathrm{HyA}$ and $c i s 18 \mathrm{ACh} \cdot \mathrm{HyA}$ complexes are depicted in Figure 10. The changes taking place in the long spacing peaks after heating at $120^{\circ} \mathrm{C}$ are very slight in both cases. In fact, no shift was perceived for $c i s 18 \mathrm{ACh} \cdot \mathrm{HyA}$ whereas a small increase in the spacing of around $0.1 \mathrm{~nm}$ could be observed for $18 \mathrm{ACh} \cdot \mathrm{HyA}$. It is worth to mention that the change observed for $18 \mathrm{ACh} \cdot \mathrm{HyA}$ happened abruptly at $\sim 60{ }^{\circ} \mathrm{C}$ revealing that the rearrangement involved in this expansion must be associated with the melting of the paraffinic phase. After cooling the initial spacing was recovered although the peak lost some intensity and became slightly broader indicating that the original order must be reduced. As expected, the behavior observed for $16 \mathrm{ACh} \cdot \mathrm{HyA}$ is almost the same as for $18 \mathrm{ACh} \cdot \mathrm{HyA}$ whereas in the cases 
of both $12 \mathrm{ACh} \cdot \mathrm{HyA}$ and $14 \mathrm{ACh} \cdot \mathrm{HyA}$, a small contraction took place upon heating and was not recovered after cooling (Figures S7 and S8 in SI). The different response given by the complexes to temperature changes can be accounted by their differences in the arrangement of the alkanoyl chain, and it is in agreement with the behavior observed for other closely related complexes previously studied..$^{22,25,27,34}$
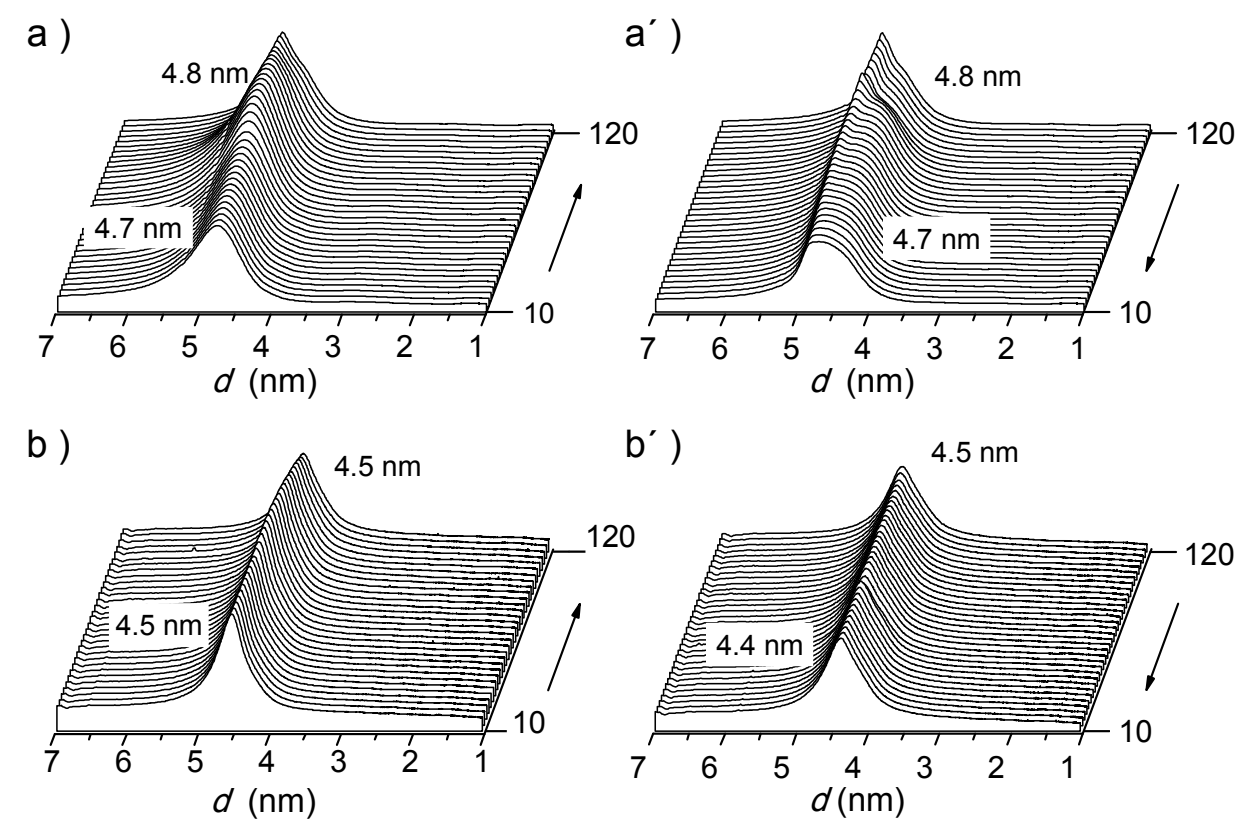

Figure 10. SAXS profiles of $18 \mathrm{ACh} \cdot \mathrm{HyA}$ (top) and cis18ACh $\cdot \mathrm{HyA}$ (bottom) at heating (a and b) and cooling ( $a^{\prime}$ and $\left.b^{\prime}\right)$ along $10-120^{\circ} \mathrm{C}$ range.

\section{Decomposition of $\boldsymbol{n} \mathrm{ACh} \cdot \mathrm{HyA}$ complexes in aqueous environment. Since $n \mathrm{ACh} \cdot \mathrm{HyA}$} complexes are designed for building nanocarriers to be used in aqueous environments, a study addressed to investigate their response to water was performed. For that purpose, $12 \mathrm{ACh} \cdot \mathrm{HyA}$ and $18 \mathrm{ACh} \cdot \mathrm{HyA}$ complexes were incubated under physiological conditions both in the presence and in the absence of hyaluronidases, and the changes taking place with time in weight, composition, and chemical constitution of the incubated samples were evaluated. In Figure 11, the sample weight remaining after incubation is plotted against the incubation time for the two 
complexes. 12ACh.HyA appeared to be highly sensitive to the presence of water so disintegration started in the first several hours of incubation and was almost complete after three days. The weight loss was much faster in the presence of hyaluronidases with the sample becomes fully disintegrated after $24 \mathrm{~h}$. The attack of water on $18 \mathrm{ACh} \cdot \mathrm{HyA}$ was much less aggressive so that only about $30 \%$ of the original weight was lost after three weeks of incubation. As before, the presence of hyaluronidases speeded up the degradation process so that the weight loss was ca. $60 \%$ after such a period of time. The much greater stability displayed by $18 \mathrm{ACh} \cdot \mathrm{HyA}$ is obviously due to the long alkanoyl surfactant chain which largely hindered the water action on the complex. For $n=18$ not only hydrophobicity is increased but the complex becomes also partially crystalline. It is worthy to note that the water degradation observed for $n \mathrm{ACh} \cdot \mathrm{HyA}$ complexes is much faster than that for their analogues made of PGGA, a difference that is reasonable provided the greater capacity of hyaluronic acid to swell which makes easier the uptake of water by the complex. ${ }^{43,44}$ The FTIR spectra recorded from the residual samples collected at increasing incubation times are compared in Figure S9 of the SI file. Strikingly, the chemical composition remained essentially unchanged and no band indicative of hydrolysis of the choline stearate was detected. On the contrary, bands arising from the hyaluronic acid increased in intensity, in particular, those associated to end groups generated upon hydrolysis of the polysaccharide. Therefore, it is preliminary concluded that decomposition involves mainly the breaking of the HyA chain with the subsequent release of ACh-coupled oligosaccharides to the aqueous medium. According to what has been reported to occur in similar complexes, ${ }^{35,47}$ it is likely that the decoupling of the ionic pair ACh-Hyal happens to some extent, either in the original complex or in the oligomeric species generated by hydrolysis. 


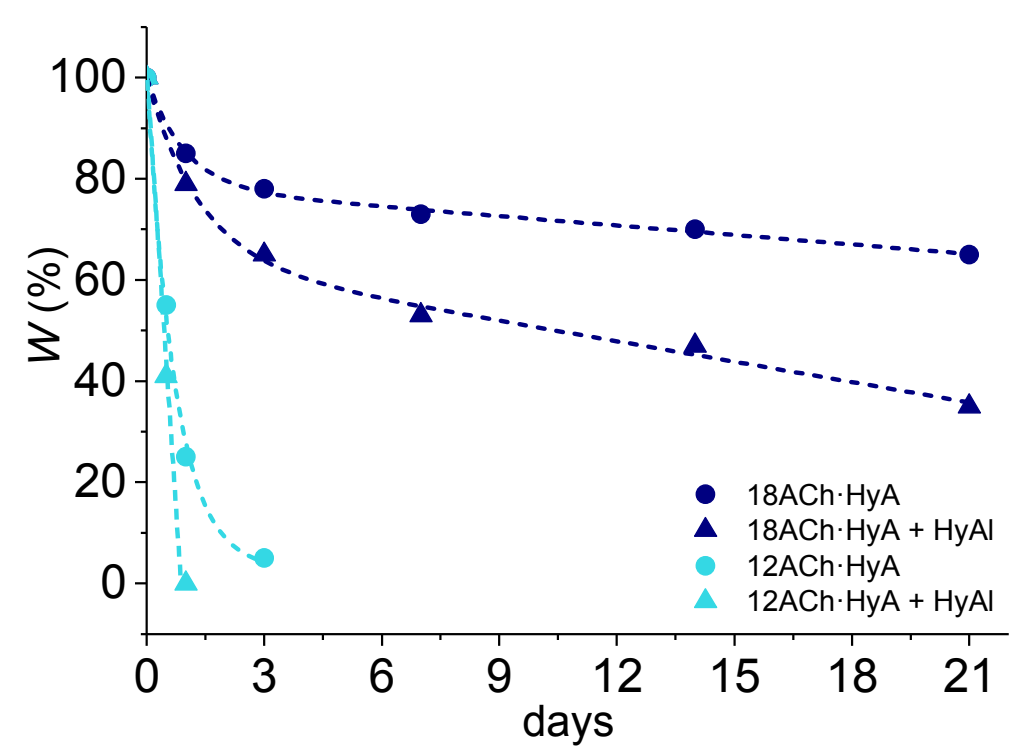

Figure 11. Weight loss undergone by $n \mathrm{ACh} \cdot \mathrm{HyA}$ complexes with $n=12$ and 18 upon incubation at $\mathrm{pH}=7.4$ at $37^{\circ} \mathrm{C}$ with and without enzymes added.

nACh·HyA nanoparticles: Characterization, stability and cytotoxicity. The preparation of NPs of $n \mathrm{ACh} \cdot \mathrm{HyA}$ for $18 \mathrm{ACh}$ and $c i s 18 \mathrm{ACh}$ surfactants has been achieved using the ionotropic gelation technique. We have used previously this technique for the preparation of NPs made of complexes of PGGA and alkanoylcholines, the which showed acceptable stability in suspension and controlled degradability in aqueous environments. ${ }^{35}$ Different experimental conditions were explored to optimize the self-assembly of the complexes in NPs whose details are given in Table $\mathrm{S} 2$ in the SI file. Nanoparticles made of $18 \mathrm{ACh} \cdot \mathrm{HyA}$ or cis $18 \mathrm{ACh} \cdot \mathrm{HyA}$ with surfactant-to-HyA ratios of 0.25 and 0.5 , which were prepared by using a concentration of $0.1 \%(\mathrm{w} / \mathrm{w})$ for the two aqueous solutions, were those displaying the best shape and size. The most relevant parameters measured for these particles are given in Table 4. No great differences were found among the different types of NPs prepared. Hydrodynamic diameters were within the narrow 135-156 nm range, with larger sizes corresponding to those with ACh:HyA ratio of 0.25 . This is according to 
the higher degree of swelling that is reasonably expected for such composition. The $\zeta$ potential significantly increased for lower contents in surfactant as it should be expected since a higher concentration of free carboxylic groups will remain on the NP surface at lower surfactant concentration. In addition, differences in $\zeta$ potential between $18 \mathrm{ACh} \cdot \mathrm{HyA}$ and $\mathrm{cis} 18 \mathrm{ACh}$ NPs were negligible indicating that the presence of the double bond affects significantly neither the size nor the charge of the NPs.

Table 4. Parameters for $\mathrm{nACh} \cdot \mathrm{HyA}$ nanoparticles

\begin{tabular}{|c|c|c|c|c|}
\hline \multirow[t]{2}{*}{ Parameters } & \multicolumn{2}{|l|}{ 18ACh $\cdot \mathrm{HyA}$} & \multicolumn{2}{|l|}{ cis18ACh $\cdot \mathrm{HyA}$} \\
\hline & $18 \mathrm{ACh} \cdot \mathrm{HyA}-0.25$ & 18ACh $\cdot$ HyA- 0.5 & 18ACh·HyA-0.25 & 18ACh $\cdot$ HyA-0.5 \\
\hline $\mathrm{Na} \cdot \mathrm{HyA}($ wt.\%) & 0.1 & 0.1 & 0.1 & 0.1 \\
\hline$n \mathrm{ACh}(\mathrm{wt} . \%)^{\mathrm{a}}$ & 0.1 & 0.1 & 0.1 & 0.1 \\
\hline ACh:HyA & $0.25: 1.0$ & $0.5: 1.0$ & $0.25: 1.0$ & $0.5: 1.0$ \\
\hline$T\left({ }^{\circ} \mathrm{C}\right)$ & 65 & 65 & 35 & 35 \\
\hline Size $(n m)^{b}$ & 149 & 143 & 156 & 135 \\
\hline $\operatorname{STD}(\%)^{\mathrm{c}}$ & 34 & 35 & 29 & 34 \\
\hline$\zeta$ potential $(\mathrm{mV})$ & -28.9 & -25.7 & -29.3 & -25.7 \\
\hline
\end{tabular}

\footnotetext{
${ }^{\text {a }}$ Concentration of the aqueous solutions used for gelation.

${ }^{\mathrm{b}}$ Average hydrodynamic diameter obtained by DLS measurements in water.

${ }^{\mathrm{c}}$ Standard deviation for DLS data.
}

Figure 12 shows TEM images of NPs made of $18 \mathrm{ACh} \cdot \mathrm{HyA}$ and cis $18 \mathrm{ACh} \cdot \mathrm{HyA}$ NPs with a ACh:HyA ratio of 0.5:1.0 and similar pictures taken for NPs with the ACh:HyA ratio of 0.25:1.0 can be found in Figure S10 in the SI file. These micrographs show essentially spherical particles, 
most of them with diameters between 50 and $100 \mathrm{~nm}$, which values are much smaller than those measured by DLS. Such differences in size are interpreted to be due to the drying underwent by the NPs under the vacuum applied for their observation in the microscope, and also to the fact that the hydrodynamic diameter is measured by DLS. Similar sizes were observed for both 18ACh $\cdot H y A$ and cis18ACh $\cdot$ HyA NPs in the TEM images despite the differences noticed by DLS. This is fully consistent with the results expected from the deswelling of the gel NPs. A close inspection of the electron micrographs showed indications on the existence of some organization of the complex in the NPs at the nanometer scale. The $18 \mathrm{ACh} \cdot \mathrm{HyA}$ nanoparticle seen on the inset of Figure 12a displays a layered arrangement with a periodicity (measured by optical diffraction) of $4.7 \mathrm{~nm}$, which is almost coincident with the value measured by SAXS for the film of this complex. A similar analysis of the NPs made of cis $18 \mathrm{ACh} \cdot \mathrm{HyA}$ revealed a granular texture (inset of Figure 12b) indicative of a different nanoscale organization.
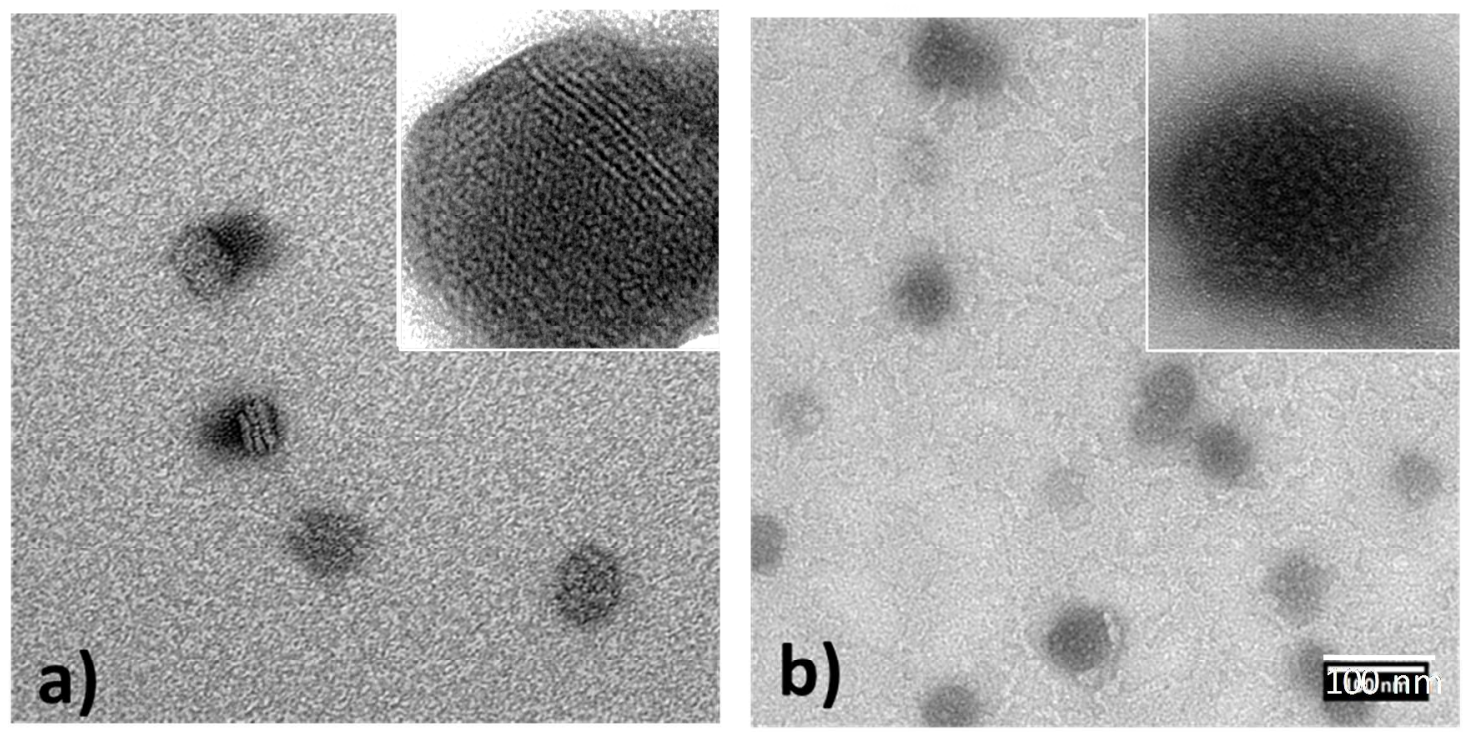

Figure 12. TEM micrographs of NPs made of $18 \mathrm{ACh} \cdot \mathrm{HyA}$ (a) and cis $18 \mathrm{ACh} \cdot \mathrm{HyA}$ (b) with a ACh:HyA ratio of 0.5 :1.0. Insets: High magnification pictures showing signs of nanometric ordering. 
The stability of the NPs in water was evaluated by measuring the changes in size taking place after incubation for 15 and 30 days at $25{ }^{\circ} \mathrm{C}$ (Figure 13). The NP size increased by more than twofold after their immersion in water for two weeks and multiplied several times after a month. This size increase was also associated with a considerable broadening in dispersity. This effect was less pronounced for cis $18 \mathrm{ACh} \cdot \mathrm{HyA} \mathrm{NPs}$, which is in principle a striking result since an easier water diffusion could be expected in these amorphous NPs. It cannot be discarded however that aggregation with subsequent collapse is favoured in $18 \mathrm{ACh} \cdot \mathrm{HyA}$ NPs due to the occurrence of specific interactions between the crystalline nanophases present in these NPs.
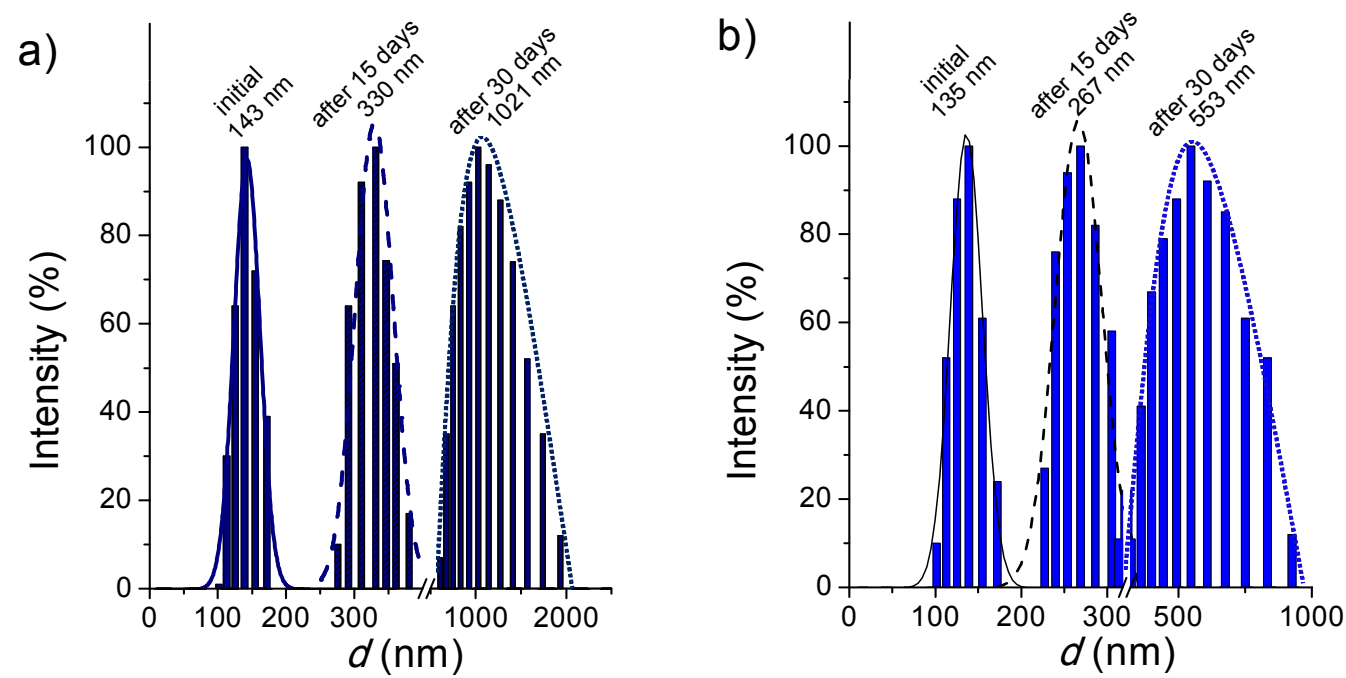

Figure 13. Size evolution of $18 \mathrm{ACh} \cdot \mathrm{HyA}$ (a) and cis18ACh·HyA (b) NPs along incubation time

The cytotoxicity of $18 \mathrm{ACh} \cdot \mathrm{HyA}$ and $c i s 18 \mathrm{ACh} \cdot \mathrm{HyA}$ nanoparticles with $\mathrm{ACh}: \mathrm{HyA}$ ratios of 0.5:1.0 and 0.25:1.0 was evaluated in vitro with raw mouse macrophages 264.7 cell line. The number of cells still alive after the incubation with the NPs were counted and compared with those present in a negative control. Figure 14 shows that the cell vitality were over $80 \%$ for all the types of NPs assayed after 4 and $24 \mathrm{~h}$ of incubation, indicating that none of the NPs displays important cytotoxicity. 


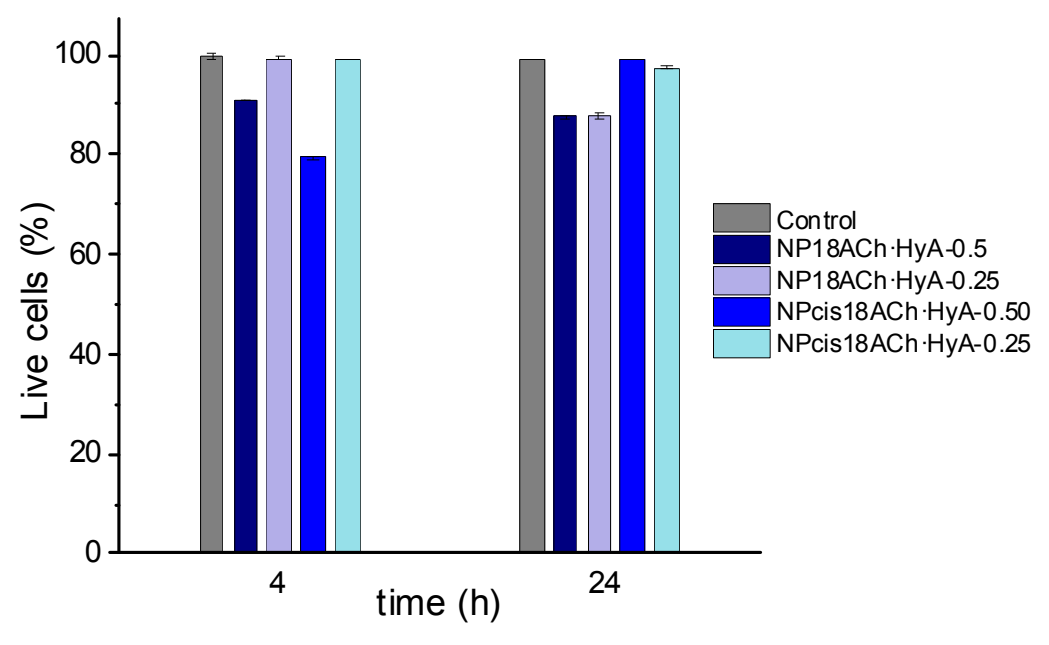

Figure 14. Cell viability of mouse macrophages cell lines 264.7 after exposure to $18 \mathrm{ACh} \cdot \mathrm{HyA}$ and $c i s 18 \mathrm{ACh} \cdot \mathrm{HyA}$ NPs with different Ach·HyA ratios. Standard deviations are less than 0.3.

\section{$n \mathrm{ACh} \cdot \mathrm{HyA}$ nanoparticles as nanocarriers: DOX loading and releasing assays. A} preliminary study of the potential use of $n \mathrm{ACh} \cdot \mathrm{HyA}$ complexes as drug delivery systems was performed by examining the loading and releasing of DOX from both films and NPs made of 18ACh·HyA and cis 18ACh·HyA. In all cases, the amount of DOX added for loading was around $5 \%$ of the complex and the entrapping efficiency was $100 \%$ and $83 \%$ for films and NPs, respectively. The delivery study was performed by incubation of the loaded films and NPs in PBS at room temperature and following the drug release along time by UV spectroscopy. The releasing profiles obtained for the two complexes are represented in Figure 15 which reveals the following: a) In all cases DOX started to be released at time 0 but with almost no burst detected, b) drug delivery happened in general at a high rate that was faster in films, c) delivery rate differences between $18 \mathrm{ACh} \cdot \mathrm{HyA}$ and $\operatorname{cis} 18 \mathrm{ACh} \cdot \mathrm{HyA}$ complexes were not significant, and d) the 
complete delivery of DOX from films was accomplished in $24 \mathrm{~h}$ whereas only $60 \%$ of the drug loaded in the NPs was released by that time.

According to the pattern displayed by the releasing profiles, the drug is expected to be entrapped inside the material since surface adsorbed drug would present an initial burst almost independent of time, which is not observed. Since DOX is assumed to be ionically coupled with HyA, it is predominantly lodged in the HyA-nanophase, which is alternating with the AChnanophase throughout the bulk of the whole particle. The different kinetic behaviour displayed by the films and NPs may be attributed to a difference in the degree of drug-HyA ionic interaction. The films were prepared by adding DOX to the solution of the complex previously formed while NPs were prepared with the DOX present during the formation of the complex. It could be expected therefore that DOX have an easier access to the HyA domains in the NPs. The DOX-HyA ionic interaction prevailing in NPs would delay the release of the drug compared to films where DOX would be physically entrapped in a greater extent.

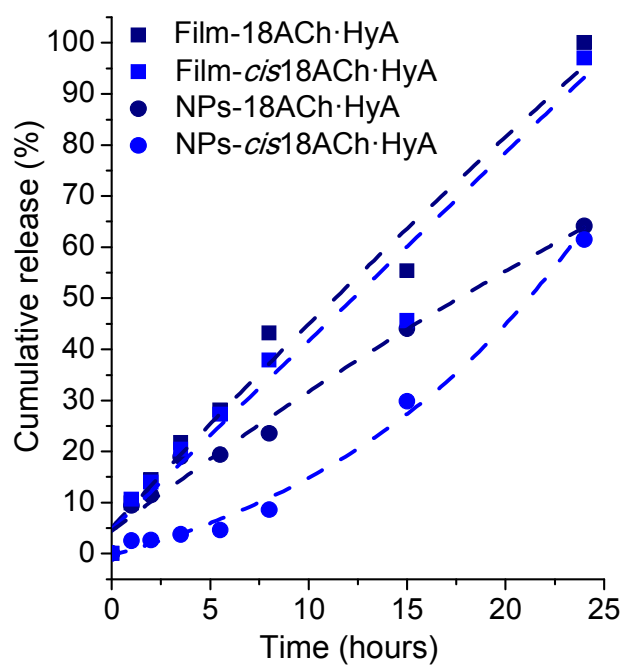

Figure 15. Drug release from films and NPs of $18 \mathrm{ACh} \cdot \mathrm{HyA}$ and $\operatorname{cis} 18 \mathrm{ACh} \cdot \mathrm{HyA}$ complexes upon incubation at $\mathrm{pH} 7.4$ and $37^{\circ} \mathrm{C}$. 


\section{CONCLUSIONS}

Ionic complexes of hyaluronic acid and alkanoylcholine surfactants ( $n \mathrm{ACh} \cdot \mathrm{HyA})$ with a comblike architecture could be successfully synthesized by applying the general coupling procedure. The $n \mathrm{ACh} \cdot \mathrm{HyA}$ complexes were water-insoluble and stable up to $c a .200^{\circ} \mathrm{C}$. These amphiphilic complexes adopted, in the solid state, an ordered nanoscale structure with the polysaccharide and the surfactant segregated in two phases alternating regularly with a periodicity of about 4-5 $\mathrm{nm}$. Since the two components of $n \mathrm{ACh} \cdot \mathrm{HyA}$ are biocompatible and biodegradable, and the complexes tend to self-assemble with the paraffinic phase segregated in a separated domain, they stand out as good candidates for building nanocarriers for both hydrophobic, neutral, and ionically charged drugs. Spherical nanoparticles with diameters about $150 \mathrm{~nm}$ could be prepared by ionotropic gelation from the complexes derived from stearoyl and oleoyl choline with ACh:HyA ratios of 0.5 and 0.25 . These nanoparticles were stable for a few days in aqueous emulsion to finally precipitate after one month of incubation. The cytotoxicity study carried out on these NPs has shown that they are biocompatible. Loading and releasing assays of DOX on NPs of $18 \mathrm{ACh} \cdot \mathrm{HyA}$ and $c i s 18 \mathrm{ACh} \cdot \mathrm{HyA}$ demonstrated a high loading efficiency and a fast but controlled drug delivery upon incubation under physiological conditions. The final conclusion is that $n \mathrm{ACh} \cdot \mathrm{HyA}$ complexes may be considered a highly promising biocompatible/biodegradable platform for the design of systems suitable for drug transport and targeted delivery in anticancer chemotherapy. 


\section{ASSOCIATED CONTENT}

Supporting Information. ${ }^{1} \mathrm{H}$ and ${ }^{13} \mathrm{C} \mathrm{NMR}$ data of $n \mathrm{ACh} \cdot \mathrm{I}$ and $n \mathrm{ACh} \cdot \mathrm{HyA}$. POM and TEM micrographs from films and particles of $n \mathrm{ACh} \cdot \mathrm{HyA}$. SAXS and WAXS profiles of $n \mathrm{ACh} \cdot \mathrm{HyA}$ for $n=12,14$ and 16. FTIR of $18 \mathrm{ACh} \cdot \mathrm{HyA}$ films degraded in aqueous medium. Details for $n \mathrm{ACh} \cdot \mathrm{HyA}$ composition calculations and experimental conditions used for $\mathrm{Np}$ preparation.

\section{AUTHOR INFORMATION \\ Corresponding Author \\ *E-mail: sebastian.munoz@upc.edu}

\section{ACKNOWLEDGEMENTS}

This work received financial support from MCINN (Spain) with Grant MAT2012-38044-C03 and MAT-2016-77345-CO3-01. XRD analyses realized in this research were carried out at the BL11 line of ALBA synchrotron (Cerdanyola del Vallès, Barcelona, Spain) with the helpful support of Dr. Christina Kamma-Lorger. The authors thank Katrin Kirchhoff and Christoph Sieber from Max Planck Institute for Polymer Research (Mainz) for his invaluable help with TEM and Dr. J. Pereira for his support with the toxicity assays. Thanks also to the MICINN for the Ph.D. grant awarded to Ana Gamarra Montes.

\section{REFERENCES}

(1) Laurent, T.C.; Laurent, U.B.G.; Fraser, J.R.E. The structure and function of hyaluronan: An overview. Immunol. Cell Biol. 1996, 74 (2), A1-A7. 
(2) Viola, M.; Vigetti, D.; Karousou, E.; D'Angelo, ML.; Caon, 1.; Moretto, P.; De Luca, G.; Passi, A. Biology and biotechnology of hyaluronan. Glycoconjugate J. 2015, 32 (3-4), 93-103.

(3) Vazquez, J.R.; Short, B.; Findlow, A.H.; Nixon, B.P.; Boulton, A.J.M.; Armstrong, D.G. Outcomes of hyaluronan therapy in diabetic foot wounds. Diabetes Res. Clin. Pract. 2003, 59 (2), 123-127.

(4) Gao, F.; Yang, C.X.; Mo, W.; Liu, Y.W.; He, Y.Q. Hyaluronan oligosaccharides are potential stimulators to angiogenesis via RHAMM mediated signal pathway in wound healing. Clin. Investig. Med. 2008, 31 (3), 106-116.

(5) Kogan, G.; Soltes, L.; Stern. R.; Gemeiner, P. Hyaluronic acid: a natural biopolymer with a broad range of biomedical and industrial applications. Biotechnol. Lett. 2007, 29, 17-25.

(6) Henrotin, Y.; Raman, R.; Richette, P.; Bard, H. Jerosch, J.; Conrozier, T.; Chevalier, X. ; Migliore, A. Consensus statement on viscosupplementation with hyaluronic acid for the management of osteoarthritis. Sem. Arth. Rheum. 2015, 45, (2), 140-149.

(7) Mattheolabakis, G.; Milane, L.; Singh, A.; Amiji, M.M. Hyaluronic acid targeting of CD44 for cancer therapy: from receptor biology to nanomedicine. J. Drug Targ. 2015, 23 (7-8), 605-618.

(8) Misra, S.; Hascall, V.C.; Markwald, R.R.; Ghatak, S. Interactions between hyaluronan and its receptors (CD44, RHAMM) regulate the activities of inflammation and cancer. Frontiers in immunology 2015, 6, 201.

(9) Huang, G.1.; Huang, H.L. Hyaluronic acid-based biopharmaceutical delivery and tumor-targeted drug delivery systems. J. Control. Release 2018, 278,122-126.

(10) Liang, J.R.; Jíang, D.H.; Noble, P.W. Hyaluronan as a therapeutic target in human diseases. Adv. Drug Deliv. Rev. 2016, 97, 186-203. 
(11) Tripodo, G.; Trapani, A.; Torre, M.L.; Giammona, G.; Trapani, G.; Mandracchia, D. Hyaluronic acid and its derivatives in drug delivery and imaging: Recent advances and challenges. Eur. J. Pharm. Biopharm. 2015, 97, 400-416.

(12) Fraser, J.R.E.; Appelgren, L.E.; Laurent, T.C. Tissue uptake of circulating hyaluronic acid - A whole body autoradiographic study, Cell Tissue Res. 1983, 233, 285-293.

(13) Kuo, J.W.; Swann, D.A.; Prestwich, G.D. Chemical modification of hyaluronic acid by carbodiimides. Bioconjug. Chem. 1991, 2 (4), 232-241.

(14) Luo, Y.; Kirker, K. R.; Prestwich, G.D. Cross-Linked hyaluronic acid hydrogel films: New biomaterials for drug delivery. J. Control. Release 2000, 69 (1), 169-184.

(15) Ossipov, D.A. Nanostructured hyaluronic acid-based materials for active delivery to cancer, Expert Opin. Drug Deliv. 2010, 7, 681-703.

(16) Dosio, F; Arpicco, S.; Stella, B.; Fattal, E. Hyaluronic acid for anticancer drug and nucleic acid delivery. Adv. Drug Deliver. Rev. 2016, 97, 204-236.

(17) Jeong, Y-L.; Kim, S-T.; Jin, S-G.; Ryu, H-H.; Jin, Y-H.; Young, T-Y.; Kim, I-Y.; Jung, S. Cisplatin-incorporated hyaluronic acid nanoparticles based on ion-complex formation. J. Pharm. Sci. 2008, $97(3), 1268-1276$.

(18) Battistini, F.D.; Flores-Martin, J.; Olivera, M.E.; Genti-Raimondi, S.; Manzo, R. H. Hyaluronan as drug carrier. The in vitro efficacy and selectivity of hyaluronan-doxorubicin complexes to affect the viability of overexpressing CD44 receptor cells. Eur. J. Pharm. Sci. 2014, 65, 122-129. 
(19) Li, W.; Yi, X.; Liu, X.; Zhang, Z.; Fu, Y.; Gong, T.; Hyaluronic acid ion-pairing nanoparticles for targeted tumor therapy. J. Control. Release 2016, 225, 170-182

(20) Ponomarenko, E.A.; Waddon, A.J.; Tirrell, D.A.; Macknight, W.J. Structure and properties of stoichiometric complexes formed by sodium poly ( $\alpha$, L-glutamate ) and oppositely charged surfactants. Langmuir 1996, 12 (9), 2169-2172.

(21) Macknight, W.J.; Ponomarenko, E.A.; Tirrel, D.A. Self-assembled polyelectrolyte-surfactant complexes in nonaqueous solvents and in the solid state. Accounts Chem.1998, 31 (12), 781-788.

(22) Pérez-Camero, G.; García-Álvarez, M.; Martínez de Ilarduya, A.; Fernández, C.; Campos, L.; Muñoz-Guerra, S. Comblike complexes of bacterial poly( $\gamma$,D-glutamic acid) and cationic surfactants. Biomacromolecules 2004, 5 (1), 144-152.

(23) García-Álvarez, M.; Álvarez, J.; Alla, A.; Martínez de Ilarduya, A.; Herranz, C.; MuñozGuerra, S. Comb-like ionic complexes of cationic surfactants with bacterial poly( $\gamma$-glutamic acid) of racemic composition. Macromol. Biosci. 2005, 5 (1), 30-38.

(24) Portilla-Arias, J.A.; García-Alvarez, M.; Martínez de Ilarduya, A.; Holler, E.; Muñoz-Guerra, S. Nanostructuresd complexes of poly( $\beta$, L-malate) and cationic surfactants: Synthesis, characterization and structural aspects. Biomacromolecules 2006, 7, 161-170.

(25) Gamarra, A.; Martínez de Ilarduya, A.; Vives, M.; Morató, J.; Muñoz-Guerra, S. Ionic complexes of poly $(\gamma$-glutamic acid) with alkyltrimethylphosphonium surfactants. Polymer 2017, 116 , 43-54. 
(26) Tolentino, A.; Alla, A.; Martínez de Ilarduya, A.; Muñoz-Guerra, S. Comb-like ionic complexes of pectinic and alginic acids with alkyltrimethylammonium surfactants. Carbohydr. Polym. 2011, $86(2), 484-490$.

(27) Tolentino, A.; Alla, A.; Martínez de Ilarduya, A.; Muñoz-Guerra, S. Comb-like ionic complexes of hyaluronic acid with alkyltrimethylammonium surfactants. Carbohydr. Polym. 2013, 92 (1), 691-696.

(28) Gamarra, A.; Forés, E.; Morató, J.; Muñoz-Guerra, S. Amphiphilic ionic complexes of hyaluronic acid with organophosphonium compounds and their antimicrobial activity. Int. J. Biol. Macromol. 2018.

(29) Chelminska-Bertilsson, M.; Allenmark, S.; Edebo, L. Butyrylcholinesterase activity towards long-chain alkanoylcholines: kinetics and mechanism. Biochim. Biophys. Acta - Protein Struct. Mol. Enzymol. 1993, 1202 (1), 56-60.

(30) Schneider, R.; Timms, A. R. Some aspects of the pharmacology of an homologous series of choline esters of fatty acids. Brit. J. Pharmacol. Chemother. 1957, 12 (1), 30-38.

(31) Alexander, J.; Fix, J.A. Enhancement of absorption of drugs from gastrointestinal tract using choline ester salts - US Pat. 4,822,773, 1989.

(32) Carelli, V.; Liberatore, F.; Scipione, L.; Cardellini, M.; Rotiroti, Domenicantonio Rispoli, V. Choline derivatives for the treatment of alzheimer's disease - Patent- WO0181296, 2001.

(33) Patel, H. Use of choline derivatives for memory, learning and cognition-WO Pat. 2005018631 A1, 2003. 
(34) Tolentino, A.; León, S.; Alla, A.; Martínez de Ilarduya, A.; Muñoz-Guerra, S. Comblike ionic complexes of poly( $\gamma$-glutamic acid) and alkanoylcholines derived from fatty acids. Macromolecules 2013, $46(4), 1607-1617$.

(35) Tolentino, A.; Alla, A.; Martínez de Ilarduya, A.; Muñoz-Guerra, S. Complexes of polyglutamic acid and long-chain alkanoylcholines: nanoparticle formation and drug release. Int. J. Biol. Macromol. 2014, 66, 346-353.

(36) Tolentino, A.; Alla, A.; Martínez de Ilarduya, A.; Font-Badía, M.; Leon, S.; Muñoz-Guerra, S. Thermal behavior of long-chain alkanoylcholine soaps. RSC Adv. 2014, 4, 10738-1075.

(37) Alkrad, J.A.; Mrestani, Y.; Stroehl, D.; Wartewig, S.; Neubert, R. Characterization of enzymatically digested hyaluronic acid using NMR, RAMAN, IR, and UV-VIS spectroscopies. $J$. Pharm. Biomed. Anal. 2003, 31 (3), 545-550.

(38) Gilli, R.; Kacuráková, M.; Mathlouthi, M.; Navarini, L.; Paoletti, S. FTIR studies of sodium hyaluronate and its oligomers in the amorphous solid phase and in aqueous solution. Carbohydr. Res. $1994,263(2), 315-326$.

(39) Kubota, H.; Nambu, Y.; Endo, T. Convenient esterification of poly( $\gamma$-glutamic acid) produced by microorganism with alkyl halides and their thermal properties. J. Polym. Sci. Part A Polym. Chem. $1995,33(1), 85-88$.

(40) Portilla-Arias, J. A.; García-Alvarez, M.; Martínez de Ilarduya, A.; Muñoz-Guerra, S. Thermal decomposition of microbial poly( $\gamma$-glutamic acid $)$ and poly( $\gamma$-glutamate)s. Polym. Degrad. Stab. 2007, $92(10), 1916-1924$. 
(41) Caspersen, M.B.; Roubroeks, J.P.; Liu, Q.; Huang, S.; Fogh, J.; Zhao, R.; Tømmeraas, K. Thermal degradation and stability of sodium hyaluronate in solid state. Carbohydr. Polym. 2014, 107 (1), 25-30.

(42) Lowry, K.M.; Beavers, E.M. Thermal stability of sodium hyaluronate in aqueous solution. $J$. Biomed. Mater. Res. 1994, 28 (10), 1239-1244.

(43) Jordan, E.F.; Feldeisen, D.W.; Wrigley, A.N. Side-chain crystallinity. I. Heats of fusion and melting transitions on selected homopolymers having long side chains. J. Polym. Sci. Part A-1 Polym. Chem. 1971, 9 (7), 1835-1851.

(44) Morillo, M.; Martínez de Ilarduya, A.; Alla, A. Comblike alkyl esters of biosynthetic poly ( $\gamma$ glutamic acid ). 2 . Supramolecular structure and thermal transitions. Macromolecules 2003, 36 (20), $7567-7576$.

(45) Shu, X.Z.; Liu, Y.; Palumbo, F.S.; Luo, Y.; Prestwich, G.D. In situ crosslinkable hyaluronan hydrogels for tissue engineering. Biomaterials 2004, 25, 1339-1348.

(46) Kablik, J.; Monheit, G.D.; Yu, L.; Chang, G.; Gershkovich, J. Comparative physical properties of hyaluronic acid dermal fillers. Dermatologic Surg. 2009, 35 (Sup 1), 302-312.

(47) Portilla-Arias, J.A.; García-Alvarez, M.; Martínez de Ilarduya, A.; Muñoz-Guerra, S. Ionic complexes of biosynthetic poly(malic acid) and poly(glutamic acid) as prospective drug-delivery systems. Macromol. Biosci. 2007, 7 (7), 897-906. 